\title{
Performance of a Supersonic Over-Wing Inlet with Application to a Low-Sonic-Boom Aircraft
}

\author{
Charles J. Trefny, ${ }^{1}$ Stefanie M. Hirt, ${ }^{2}$ and Bernhard H. Anderson ${ }^{3}$ \\ NASA Glenn Research Center, Cleveland, Ohio, 44135 \\ Lawrence E. Fink ${ }^{4}$ \\ Boeing Research and Technology, Seattle, Washington, 98124 \\ and \\ Todd E. Magee ${ }^{5}$ \\ Boeing Research and Technology, Huntington Beach, California, 92647
}

Development of commercial supersonic aircraft has been hindered by many related factors including fuel-efficiency, economics, and sonic-boom signatures that have prevented over-land flight. Materials, propulsion, and flight control technologies have developed to the point where, if over-land flight were made possible, a commercial supersonic transport could be economically viable.

Computational fluid dynamics, and modern optimization techniques enable designers to reduce the boom signature of candidate aircraft configurations to acceptable levels. However, propulsion systems must be carefully integrated with these low-boom configurations in order that the signatures remain acceptable. One technique to minimize the downward propagation of waves is to mount the propulsion systems above the wing, such that the wing provides shielding from shock waves generated by the inlet and nacelle. This topmounted approach introduces a number of issues with inlet design and performance especially with the highly-swept wing configurations common to low-boom designs.

A 1.79\%-scale aircraft model was built and tested at the NASA Glenn Research Center's 8-by 6-Foot Supersonic Wind Tunnel (8x6 SWT) to validate the configuration's sonic boom signature. In order to evaluate performance of the top-mounted inlets, the starboard flow-through nacelle on the aerodynamic model was replaced by a $2.3 \%$-scale operational inlet model. This integrated configuration was tested at the 8x6 SWT from Mach 0.25 to 1.8 over a wide range of angles-of-attack and yaw. The inlet was also tested in an isolated configuration over a smaller range of angles-of-attack and yaw. A number of boundary-layer bleed configurations were investigated and found to provide a substantial positive impact on pressure recovery and distortion.

Installed inlet performance in terms of mass capture, pressure recovery, and distortion over the Mach number range at the design angle-of-attack of 4-degrees is presented herein and compared to that at 0degrees, as well as the isolated inlet configuration to highlight installation effects. Performance of the installed inlet fell below that of the isolated inlet at Mach numbers of 1.4 and greater. The installed inlet demonstrated adequate operability over the expected range of angles-of-attack and yaw, but did exhibit definite angle-ofattack and yaw limits at supersonic conditions. At each supersonic flight Mach number, performance parameters near zero yaw angle were relatively insensitive to yaw, but in general the yaw angle yielding best

\footnotetext{
${ }^{1}$ Aerospace Engineer, Inlets and Nozzles Branch, Mail Stop 5-11, 21000 Brookpark Rd, Senior Member AIAA

${ }^{2}$ Aerospace Engineer, Inlets and Nozzles Branch, Mail Stop 5-11, 21000 Brookpark Rd, Member AIAA

${ }^{3}$ Aerospace Engineer, Inlets and Nozzles Branch, Mail Stop 5-11, 21000 Brookpark Rd

${ }^{4}$ Senior Principal Engineer, Flight Sciences, P.O.Box 3707/MC 42-51, Senior Member AIAA

${ }^{5}$ Boeing N+2 Experimental Validation Project Principal Investigator, Flight Sciences, 5301 Bolsa Ave/MC H017-

D334, Senior Member AIAA
} 
performance was non-zero and varied with angle-of-attack. Performance of the installed inlet is also presented as functions of angle-of-attack and yaw to highlight these effects. Distortion at the aerodynamic interface plane ranged between 10 and $25 \%$ at the inlet critical points over the range of flight Mach numbers tested and did not decrease significantly for the isolated inlet. Although these distortion levels would be considered high for operation with a turbine engine, the over-wing installation is likely not as significant a contributor as the low test Reynolds number. This is demonstrated by comparing CFD analysis of the isolated inlet at test scale with that at intermediate and full scales.

\section{Nomenclature}

\begin{tabular}{|c|c|}
\hline$A_{0}$ & $=$ Freestream cross-sectional area of the capture stream tube, in $^{2}$ \\
\hline$A_{1}$ & $=$ Cross-sectional area of the capture stream tube approaching the inlet, in ${ }^{2}$ \\
\hline$A_{C}$ & $=$ Inlet capture area, in ${ }^{2}$ \\
\hline AIP & $=$ Aerodynamic interface plane \\
\hline$D E S$ & $=$ Detached-eddy simulation \\
\hline DIST & $=$ Total pressure distortion at the aerodynamic interface plane $\left(\mathrm{P}_{\mathrm{T}, \max }-\mathrm{P}_{\mathrm{T}, \min }\right) / \mathrm{P}_{\mathrm{T}, \mathrm{avg}}$ \\
\hline MFP & $=$ Mass flow plug \\
\hline$M_{0}$ & $=$ Nominal Mach number \\
\hline$M_{T S}$ & $=$ Test section Mach number \\
\hline$P_{T}$ & $=$ Total pressure, $\mathrm{lb} / \mathrm{in}^{2}$ \\
\hline$P_{T 0}$ & $=$ Freestream total pressure, $\mathrm{lb} / \mathrm{in}^{2}$ \\
\hline$P_{T 2}$ & $=$ Average total pressure at the aerodynamic interface plane, $\mathrm{lb} / \mathrm{in}^{2}$ \\
\hline$Q_{0}$ & $=$ Dynamic pressure, $\mathrm{lb} / \mathrm{ft}^{2}$ \\
\hline Re & $=$ Unit Reynolds number, $1 / \mathrm{ft}$ \\
\hline$R E C$ & $=$ Inlet total pressure recovery \\
\hline$T_{T 0}$ & $=$ Freestream Total temperature, $\mathrm{R}$ \\
\hline$\alpha$ & $=$ Nominal angle-of-attack, degrees \\
\hline$\alpha^{\prime}$ & $=$ Corrected model angle-of-attack, degrees \\
\hline$\Delta \alpha$ & $=$ Sting deflection, degrees \\
\hline$\beta$ & $=$ Yaw angle, positive nose-right, degrees \\
\hline
\end{tabular}

\section{Introduction}

Development of commercial supersonic flight has been hindered by many related factors including fuelefficiency, economics, and sonic-boom signatures that have prevented over-land flight. Materials, propulsion, and flight control technologies have developed to the point where, if over-land flight were made possible, a commercial supersonic transport could be economically viable. Interest in over-land supersonic flight therefore forms the basis of a National Aeronautics and Space Administration (NASA) program to reduce sonic boom to acceptable levels. This research program is led by the High Speed Project under NASA's Fundamental Aeronautics Program in cooperation with a number of U.S. aircraft manufacturers.

Computational fluid dynamics, and modern optimization techniques enable designers to reduce the boom signature of candidate aircraft configurations to acceptable levels. However, propulsion systems must be carefully integrated with these low-boom configurations in order that the signatures remain acceptable. One technique to minimize the downward propagation of waves is to mount the propulsion systems above the wing, such that the wing provides shielding from shock waves generated by the inlet and nacelle. This top-mounted approach introduces a number of issues with inlet design and performance especially with the highly-swept wing configurations common to low-boom designs. An example of one such design is Boeing's Mach 1.6 Quiet Experimental Validation Concept (QEVC), shown in Fig. 1 being developed for ultimate application to the business-class commercial transport 
market, and also initially as a candidate for demonstration of low-boom, over-land flight.

As part of the QEVC development, a 1.79\%-scale aircraft model was built and tested at the NASA Ames

Research Center's 9-by 7-Foot Supersonic Wind Tunnel and the NASA Glenn Research Center's 8-by 6-Foot Supersonic Wind Tunnel (8x6 SWT) to validate the configuration's sonic boom signature. In order to evaluate performance of the top-mounted inlets, the starboard flow-through nacelle on the aerodynamic model was replaced by a $2.3 \%$-scale operational inlet model. Results of this inlet performance testing are reported herein. It should be noted that given the small model scale, sparse instrumentation and associated Reynolds number mismatch, the objectives of this test program were more of a proof-of-concept nature than an attempt to obtain detailed performance or code validation information.

The inlet itself is of a class of Boeing designs known as the "Elliptical Cowl Ramp Inlet (ECRI)." The QEVC aircraft is designed for Mach 1.6 flight, at an altitude of 48,000-feet and a nominal angle-of-attack of 4degrees. Flow at the over-wing inlet location was assumed uniform and estimated to be Mach 1.66, thus the ECRI inlet was designed for Mach 1.71 shock-on-lip to allow some excursion in flight Mach number and angle-of-attack. It is a 3-ramp, external-compression inlet design with ramp angles of 4.67, 9.44, and 13.99-degrees. A design-ofexperiments approach was used to develop basic inviscid 3-D inlet contours, which were optimized with a morphing-grid RANS CFD approach for a balance of high critical total pressure recovery, low distortion, and low cowl drag in the installed configuration. This resulted in the topology shown in Fig. 2. Note the w-shaped, wavy surface of the ramp in the transverse direction, required to focus shocks on the elliptical cowl in the presence of three-dimensional corner flows generated at the ramp-cowl juncture. Additional details can be found in Ref. 1 .

\section{Wind-Tunnel Model and Test Procedure}

\section{A. Model and Instrumentation}

The 1.79\%-scale QEVC aerodynamic model had a wingspan of 19", and was 43" long. The starboard flowthrough nacelle was replaced by a $2.3 \%$-scale operational inlet model. The increased scale of the inlet model relative to the aircraft was necessitated by a minimum aerodynamic interface plane (AIP) diameter of 1.5 -inches needed to accommodate the blockage of the standard 40-probe AIP instrumentation array. Figures 3 and 4 show the model installed in the 8x6 SWT. The aircraft model and mass flow plug (MFP) were mounted independently to a central sting that was coincident with the facility mounting sting and the aircraft longitudinal axis. The axis of the cylindrical MFP was offset from and parallel to the aircraft longitudinal axis. The inlet model incorporated a twodegree toe-out to better align the aperture with the over-wing flowfield. It was also rotated 10.33-degrees to align it with the wing dihedral. The inlet was mounted on a boundary-layer diverter such that the ramp leading edge was offset 0.034 -inches from the wing surface. To insure boundary-layer transition upstream of the inlet, grit strips were applied at the wing leading edges and nose tip. The wing grit strips were 0.10 -inches wide, and applied 0.125 -inches from the wing leading edge (measured perpendicular to the leading edge). At the nose tip, another 0.10 -inch wide grit strip was applied 1-inch downstream of the tip. 120-size grit at approximately 150 grains per square inch was applied to a thin layer of epoxy to create these grit strips.

The inlet was also tested in the isolated configuration pictured in Fig. 5, with the aircraft model removed, and the MFP and sting rotated to the orientation shown, with the MFP at top dead center above the sting, and the inlet horizontal. Since the 2-degree toe-out required for the over-wing inlet integration was built into the inlet model section, the effective yaw angle at the inlet aperture was 2-degrees. This necessitated a negative 2-degree yaw angle to be set during testing in order that the inlet aperture be at zero yaw.

The inlet and mass flow plug assembly is pictured in Fig. 6 and consisted of three major components: the inlet model, the calibrated mass flow plug used to provide back-pressure and measure airflow, and an axisymmetric adapter section connecting the 1-1/2-inch diameter inlet exit to the two-inch diameter MFP. The entrance to the adapter section also defined the AIP and housed the instrumentation used to evaluate inlet performance.

The inlet model had a capture area of 1.5631 square inches, and the boundary-layer diverter leading edge 
was offset 0.034 -inches from the wing upper surface. The inlet was equipped with the four bleed zones pictured in Fig. 7 consisting of one on the forward ramp, one in the diffuser, and one on each sidewall. All bleed regions consisted of .020-inch diameter normal holes at roughly $10 \%$ porosity and a length-to-diameter ratio of 3 . Total bleed area in terms of percent of capture area was 3.6\% and 3.2\% for the ramp and diffuser bleeds respectively, and $1.7 \%$ and $1.3 \%$ for the inboard and outboard sidewalls respectively. Separate plenums beneath the ramp and diffuser bleeds were evacuated by slots on the diverter edge, angled at 45-degrees as pictured in Fig. 7. The sidewall bleed holes were drilled directly through the sidewall, allowing bleed flow to exhaust directly to the local freestream. Estimates of bleed flow rates for each of the regions were made based on the pressure ratio across the bleed region using the technique of Ref. 2. The sidewall bleed pressure ratios were measured by static taps on both the internal and external surfaces, immediately downstream of the perforated regions. The ramp and diffuser bleed pressure ratios were evaluated using a static tap in each of the plenums and a single tap on the ramp surface between the bleed regions. This single tap did not well represent the actual pressure over the perforated regions for much of the range of back-pressures. This position error, leaks that developed in a number of taps, and the approximate nature of the method rendered bleed flow measurements unreliable. A separate inlet model without provisions for bleed was also available. This model was used in the first series of tests to evaluate installed inlet performance with no bleed. Unfortunately, an error in the 8x6 SWT flex-wall settings rendered the bulk of these data invalid, and none of the no-bleed inlet data is used for comparisons herein. In subsequent tests with the bleed inlet, the back-side of the perforated bleed plates, as well as the bleed exits were taped-over to explore various bleed configurations.

A standard, area-weighted 40-probe array, pictured in Fig. 8 was used to measure pressure recovery and distortion at the AIP. The rakes at 0,90,180, and 270-degrees had an additional tube adjacent to the middle probe that housed a high-frequency transducer intended to indicate buzz onset. Only one of these transducers survived to the end of the test program, but did provide the desired indication of inlet buzz. The degree to which this additional tube affected the pitot pressure measurement is unknown, but by inspection of rake data is thought to be minimal. Eight wall static pressures were located at the midpoints between rakes in the plane of the pitot probe tips.

The mass flow plug assembly, used to back-pressure the inlet and measure airflow, was driven by an electric motor and equipped with an LVDT position sensor. Plug position was calibrated, and checked each test day for accuracy. The mass flow plug was equipped with four, three-probe, area-weighted total pressure rakes at approximately the mid-point between the entrance and throat. Pictured in Fig. 9, each of these rakes had an additional total temperature probe between the two probes closest to the axis. The rakes were indexed 22.5-degrees counter-clockwise from the cardinal directions (looking forward) in order to be in-between the AIP rakes. This rake array was used to evaluate the average total pressure approaching the MFP. This average was used during calibration to determine corrected flow as a function of plug position and pressure ratio. The calibration was performed at a Boeing facility in Seattle over the full range of plug travel for pressure ratios from 1.1 to 7 with atmospheric exhaust. Reynolds number effects were not determined, nor accounted in the data reduction. For the research runs at the 8x6 SWT, four base pressure taps were installed under the aft fairing near the plug exit in order to evaluate MFP nozzle pressure ratio for un-choked cases.

\section{B. 8x6 Facility and Model Installation}

Tests were conducted in the 8- by 6-Foot Supersonic Wind Tunnel (8x6 SWT) described in Ref. 3. The 8x6 SWT, at the NASA Glenn Research Center in Cleveland, Ohio, is a continuous-flow facility powered by a sevenstage axial compressor. It can run in closed-loop (aerodynamic) or open-loop (propulsion) modes. Propulsion mode is employed if combustion products or other exhaust is emitted by the test article. For the test program described herein, the aerodynamic mode was used exclusively. The test section is eight-feet high, six-feet wide, and 24-feet, 6inches long. The downstream 14-feet, 5-inches of the test section is perforated for transonic testing. The entire test section is housed in a balance chamber to control pressure outside the perforated section. Test section Mach number is continuously variable from 0.25 to 1.3 and in 0.1 increments from Mach 1.3 to 2 . Supersonic Mach number is set by the flexible-wall nozzle upstream of the test section. The test program was run at discrete nominal freestream Mach of 0.8 to 1.8, with a limited number of runs at Mach .25 to represent take-off and landing conditions. Table 1 presents the actual test conditions in the 8x6 SWT as a function of the nominal Mach number. 
The model was supported by a sting which incorporated a roll mechanism. This sting was in turn mounted to the facility strut which penetrated the test section floor and provided angle-of-attack capability. With this arrangement, the model nose tip was roughly three feet downstream of the start of the perforated transonic test section. Using the appropriate combinations of pitch and roll, the model was tested over the range of -2 to +8 degrees angle-of-attack $(\alpha)$, and -6 to +6 -degrees yaw angle $(\beta)$ where positive $\alpha$ is nose-up, and positive $\beta$ is nose right. Ordinal values of $\alpha$ and $\beta$ were set as per the test matrix, and $\alpha$ was corrected for sting deflection.

The sting was instrumented with strain gauges and calibrated during installation for deflection due to lift. The strain gauges failed during the first series of runs after only a few angle-of-attack settings at Mach 1.8. A spring constant for the sting was subsequently developed using the indicated deflections prior to failure, and lift coefficient data from a previous aerodynamic test program with the same model. The spring constant so obtained was then used to estimate the sting deflection for all combinations of Mach number and angle-of-attack. The resulting sting deflections were a very weak function of freestream Mach number since dynamic pressure increases with Mach number in the 8x6 SWT, and compensates for a reduction in lift coefficient. A linear fit of sting deflection versus $\alpha$ is within $+/$ - 0.1-degrees for all test conditions and model attitudes reported herein. Sting deflection and the resulting actual $\alpha$ are presented in Table 2 as a function of the ordinal values of $\alpha$.

\section{Data System and Uncertainty}

All measured and calculated parameters were scanned and updated once each second by the Escort data system at the $8 \times 6$ SWT. Accuracy of pressure measurements is $+/-0.015$ psia at the transducers and does not contribute substantially to any error in calculated parameters. However, pneumatic lag in pressure tubing can cause significant error as model attitude and plug position are varied. To ensure the accuracy of these parameters, as well as all other pressure measurements, the standard deviation of the last 5 scans for each pressure was monitored as each test condition was set. A 5 to10-second dwell was required at each plug position before the standard deviations reached equilibrium and data was recorded. The standard deviation values approached 1 to 2 -times the measurement accuracy as expected, unless the inlet flow was unsteady such as for high model attitude angles and sub-or supercritical inlet conditions. Uncertainty in the pressure recovery and distortion values reported herein is thereby considered negligible for steady flow conditions. Accuracy of inlet critical-point values for these parameters is however affected by the finite resolution of the inlet characteristics near the critical points. Reported critical-point values of recovery and distortion are estimated to be within $0.25 \%$ of the true value due to this effect.

Mass flow ratio reported herein is a function of the corrected flow rate reported by the calibrated MFP. Its uncertainty is complicated by the fact that the test and calibration installations differed in a number of ways. In the $8 \times 6$ SWT installation, the MFP rake station where stagnation pressure is evaluated, is only about 2 or 3 diameters downstream of the AIP based on MFP or AIP diameters respectively. Distorted flow at the AIP during research runs therefore did not equilibrate to the axisymmetric flow of the calibration. This lack of similarity between calibration and research runs adds to the uncertainty in reported mass flow. At subsonic flight conditions, the MFP was unchoked, and the measured base pressures were used to evaluate the pressure ratio. Any difference between the measured base pressure and that of the quiescent exit environment of the calibration adds to the uncertainty for unchoked conditions. The limited number of runs made at Mach 0.25 had very low MFP pressure ratio, where the sensitivity of corrected flow to pressure ratio was high, adding to the uncertainty at this test condition. Given these factors, a definitive statement cannot be made on the uncertainty for inlet mass flow ratio, other than it is greater than the base uncertainty of the calibration which was $+/-0.1 \%$. Given the variation in reported mass flow ratios during supercritical inlet operation, and the fact that the measurements were not of sufficient resolution to discern bleed flows, the uncertainty in reported mass flow is estimated to be $+/-1.0 \%$.

Mach number in the transonic test section volume is within 0.05 of the stated test section Mach number $\left(\mathrm{M}_{\mathrm{TS}}\right)$. Flow angularity is +/- 0.5-degrees, and total temperature varies by less than 4-degrees R. Additional flow quality and calibration information can be found in Ref. 4.

Pitch and roll, used to set model angles-of-attack and yaw, were calibrated at model installation and checked each run day. Pitch and roll values are accurate to within 0.01 and 0.40 -degrees respectively. The resulting uncertainties in nominal angle-of-attack, $\alpha$ and yaw angle, $\beta$ are 0.05 and 0.06 -degrees respectively. Accounting for 
inaccuracy in the aforementioned sting deflection estimates, the uncertainty in corrected model angle-of-attack, $\alpha^{\prime}$ is $+/-0.15$-degrees.

\section{Test Procedure}

The test program consisted of three phases. The first was an exploration of various installed inlet bleed configurations. It was determined that the diffuser bleed was the most effective and the second phase of testing was to map performance of this configuration over the range of model attitudes and freestream Mach numbers. The final phase of testing with the isolated inlet configuration provided limited data for comparison to the installed inlet. Isolated inlet tests were run with both diffuser bleed, and with the bleeds sealed. Time and budget constraints did not allow for a complete mapping of performance, or comprehensive comparisons of installed and isolated configurations. Table 3 presents the final matrix of conditions run with the installed inlet with diffuser bleed. Note that "S" denotes the points where a direct comparison between the installed and isolated configurations can be made. These comparisons are made with the isolated inlet at a -2-degree yaw offset from the installed, to compensate for the inherent 2-degree toe-out in the inlet geometry.

At each condition, the mass flow plug was actuated to determine inlet performance as a function of backpressure from super-to sub-critical conditions. Approximately ten data points were recorded in each mass flow plug sweep to generate the inlet "cane" curve. These were concentrated around the critical point in order to accurately define it for each test condition. Back-pressure was increased until airflow was 15-20\% below the critical value, or buzz occurred. The inlet critical point is defined as the point of maximum total pressure recovery at the maximum total mass capture, i.e. a point just prior to subcritical spillage at the cowl lip.

\section{Results and Discussion}

\section{A. Effect of Bleed}

The first phase of testing was dedicated to screening various combinations of sidewall, ramp, and diffuser bleeds. The limited instrumentation available to evaluate bleed flow rate indicated negligible delta-P, and therefore flow, across the sidewall and ramp bleed regions. This was corroborated by a negligible effect on inlet performance. The diffuser bleed region however did indicate a bleed flow of approximately one-percent or less depending on back-pressure and had a significant effect on inlet pressure recovery and distortion. Figure 10 compares inlet airflow characteristics between no-bleed and diffuser bleed cases for the installed inlet configuration. The Mach 1.2 cases indicate that recovery is $2 \%$ higher at the critical point with bleed for both the 4 and 6-degree angle-of-attack cases. At Mach 1.6, the effect of diffuser bleed is more pronounced, improving recovery by $3-4 \%$. In general, bleed flow rate cannot be discerned as a difference in mass flow ratios between the bleed and no-bleed cases. Some of the bleed cases exhibit a slight reduction in mass flow ratio as the critical point is approached. This may be attributable to the effect of decreasing distortion on the mass flow plug calibration, but may also be due to increased bleed flow as the perforated region is pressurized. This, along with results based on delta-p and the Ref. 2 correlation, support the bleed flow rate estimate of one-percent or less.

Other trends that warrant mention are the reduction in recovery and mass flow ratio with angle-of-attack at a given freestream Mach number. The expected trend of increasing mass flow ratio and decreasing recovery as flight Mach number increases is also apparent. These will be explored further in subsequent discussion. Figure 11 presents similar results for the isolated inlet, albeit at 4 and 0-degrees angle-of-attack, and Mach 1.6 and 1.8. The same 3\% improvement in recovery due to diffuser bleed is seen at Mach 1.6, and a slightly greater improvement is evident at Mach 1.8. The trends with angle-of-attack and flight Mach number are similar to those of the installed inlet. Only at Mach 1.6 and 4-degrees angle-of-attack, do Fig.s 10 and 11 show a direct comparison between the installed and isolated inlets. For this case, the isolated inlet shows a slight recovery advantage at the critical point, with an indiscernible difference in mass flow ratio. Finally, given the Mach 1.71 shock-on-lip design point, it would be expected that the isolated inlet would be at full capture at the Mach 1.8, zero angle-of-attack condition. Possible 
reasons for the 2-3\% spillage include cowl lip bluntness coupled with the low Reynolds number, and differences between as-drawn and as-built geometries since the capture area was not directly measured.

In order to present critical-inlet performance trends, a critical point was defined on the inlet cane at each condition of interest. The uncertainty in diffuser exit and bleed flow rate measurements made it difficult to define the critical point in some cases. A number of parameters were thus examined as a function of mass flow plug position to determine the last point prior to sub-critical spillage. Criteria included a reduction in mass flow ratio as reported by the calibrated plug, a sudden increase in inlet sidewall external pressures, and an inflection point in the diffuser bleed plenum pressure as it increased with back pressure.

As stated earlier, MFP sweeps were terminated at mass flow ratios $15-20 \%$ below the critical value, or the onset of buzz. The test matrix was not designed to map inlet buzz characteristics, but it did occur at several conditions and some general statements can be made. First, buzz was only observed at Mach 1.6 and 1.8. Frequencies at Mach 1.6 ranged from $75-200 \mathrm{~Hz}$, and 120-260 Hz at Mach 1.8. There seemed to be no correlation between model attitude and the onset of buzz. Many low attitude angle cases buzzed, while some high-angle cases did not. Similarly, there was no correlation with model configuration, installed or isolated, nor bleed configuration. It is possible however, that the inlet was not pushed far enough sub-critical in each case that buzz onset would have occurred. It should also be pointed out that the test Reynolds numbers were far below those at full scale, and a more comprehensive study at larger scale would have to be undertaken to map the buzz limits and determine accurate frequencies.

Figure 12 compares AIP total pressure recovery contours at the inlet critical point for a flight Mach number of 1.6. No-bleed and diffuser-bleed cases are shown as a function of angle-of-attack for the installed and isolated configurations. At the nominal design angle-of-attack of 4-degrees, the effect of bleed is obvious from a qualitative standpoint, nearly eliminating a separated region on the ramp side of the diffuser. A significant reduction in distortion values is also evident as bleed reduces DIST by at least $30 \%$ for both the installed and isolated configurations. Increasing angle-of-attack is clearly seen to increase the deficit region near the ramp surface, with the effect being non-linear beyond about 6-degrees. It is also of interest to note that isolated inlet flow profiles are very similar to those of the installed configuration especially at low angle-of-attack. Given the poor performance without bleed, the balance of this paper will examine critical-point performance of the installed inlet with diffuser bleed. Comparisons to the isolated inlet will be included where possible.

\section{B. Sensitivity of Installed Inlet Performance to Yaw Angle for Various AOA}

Figures 13 through 15 present the effect of yaw angle on installed inlet performance at the critical point for various angles-of-attack. For conditions at which isolated inlet performance is available, it is overlaid as smaller, filled symbols. Figure 13 shows in general that the sensitivity of mass flow ratio to yaw angle increases with freestream Mach number and angle-of-attack. At the design condition of Mach 1.6 and 4-degrees angle-of-attack, the maximum airflow occurs at 2-degrees yaw angle, the mass flow ratio is relatively symmetric about that point, and there are no sharp reductions in airflow over the range of yaw angles tested. At 6-degrees angle-of-attack, there is insufficient resolution for a definitive conclusion, but a local maxima at a small positive yaw angle cannot be ruled out. A sharp reduction in airflow occurs as angle-of attack increases beyond 6-degrees for the supersonic freestream Mach numbers shown. Isolated inlet airflows are within one-percent of the installed values, however, no comparisons are available beyond +/-2-degrees yaw angle. It is notable that the isolated inlet airflow at Mach 1.6 and 4-degrees angle-of-attack closely matches that of the installed inlet.

The effect of yaw angle on total pressure recovery shows trends similar to the airflow in Fig. 14. For the design condition of Mach 1.6, and 4-degrees angle-of-attack, the recovery also maximizes at a yaw angle of 2degrees. Unlike the airflow characteristic however, the recovery decreases relatively abruptly beyond +/-4-degrees yaw angle, indicative of diffuser flow separation, for the 4-degree angle-of-attack case, and presumably for the 6degree case where some license has been taken with the trend line. For all three freestream Mach numbers, there is little sensitivity to yaw angle for angle-of-attack less than 4-degrees over the range of yaw angles tested. At zero degrees yaw, recovery decreases abruptly beyond 6-degrees angle-of-attack for the supersonic freestream cases, consistent with the contour plots of Fig. 12. The isolated inlet pressure recoveries are within one-percent for the 
Mach 1.2 and 1.6 cases.

In Fig. 15, distortion trends mirror those of pressure recovery. For the Mach 1.6, 4-degree angle-of-attack design point, the distortion is minimum at 2-degrees yaw angle, and increases abruptly for yaw angles greater than 4-degrees. Similar behavior is presumed for the 6-degree angle-of-attack case, where again, some license is taken in fitting the available data and the limits are approximately +/-3-degrees. For angles-of-attack less than 4-degrees, the distortion is insensitive to yaw over the range tested. Also consistent with recovery and airflow trends is the 6degree angle-of-attack "cliff" for supersonic freestream conditions beyond which a non-linear increase in distortion is evident. Distortion values for the isolated inlet are not substantially different from those of the installed inlet at Mach 1.6, and are slightly higher in some cases for Mach 1.2. Given the simple distortion parameter being used, these differences are insignificant.

Critical-point pressure recovery contours at the AIP for two yaw angle sweeps are presented next to show the character of the distortion and how it changes with yaw angle. Figure 16 depicts the Mach 1.6, 4-degrees angleof-attack design point, showing that the distortion is primarily due to a deficit region at 180-degrees that grows with increasing yaw angle. Recalling that positive yaw is nose-right, and noting that the view is looking upstream, any total pressure deficit due to yaw would tend to be on the left side for positive yaw, and the right side for negative. The individual plots are arranged symmetrically about zero yaw angle, but consistent with the previous discussion, the deficit region exhibits a small range of symmetry about the 2-degree point, with marked increases at $+/$ - 6 degrees. Figure 17 presents similar data at 0 -degrees angle-of-attack. Deficit regions are smaller in this case and appear to be symmetric about 0-degrees yaw angle. As with the mass flow ratio, recovery, and distortion characteristics shown above, there is little sensitivity to yaw angle at 0 -degrees angle-of-attack.

To summarize the effect of yaw angle, sensitivity of inlet performance to yaw angle increased with both flight Mach number and angle-of-attack. At Mach 1.6, operational yaw angle limits based on abrupt increases in distortion, and reductions in recovery were evident, and the operational range narrowed as angle-of-attack increased. At the design angle-of-attack of 4-degrees, this range was +/-4-degrees and performance was relatively insensitive to yaw angle in this range, however the best performance was obtained at low positive yaw angles. A definite angle-ofattack limit of 6-degrees was also evident for the Mach 1.2 and 1.6 conditions and this is explored further in the next section.

\section{Sensitivity of Installed Inlet Performance to AOA at Zero Yaw Angle}

The effect of angle-of-attack at zero yaw angle on the inlet critical mass flow ratio is shown in Fig. 18. The mass flow ratio is well-behaved for all subsonic flight conditions over the range of angles-of-attack tested. The Mach 1.2 through 1.6 flight conditions exhibit relatively constant mass capture over a range of angles-of-attack. Non-linear behavior is observed beyond 4 to 6 degrees for Mach 1.2 to 1.6. As expected, mass capture for the isolated inlet matches that of the installed configuration at zero degrees angle-of-attack. The Mach 1.8 characteristic differs from the rest in its pronounced negative slope over the 0 -to 4-degree range. This is an interesting over-wing inlet installation effect that warrants further discussion. As angle-of-attack increases, the local Mach number at the over-wing inlet location increases. There is an attendant increase in the local inlet mass flow ratio until a shock-onlip condition is reached, beyond which the inlet is over-sped and local mass flow ratio remains at unity. The overall mass flow ratio, $A_{0} / A_{C}$ however is the product of the local mass flow ratio, and the stream tube expansion over the wing leading edge. These competing effects cause $\mathrm{A}_{0} / \mathrm{A}_{\mathrm{C}}$ to be relatively constant over a range of angles-of-attack for flight conditions from Mach 1.2 to 1.6. However, at Mach 1.8 the inlet is over-sped at 0-degrees angle-of-attack and $\mathrm{A}_{0} / \mathrm{A}_{\mathrm{C}}$ begins to decrease immediately with pitch due to the aforementioned expansion over the wing leading edge. Insight into the magnitude of this leading edge expansion effect can be gained from the simple twodimensional analysis presented in Fig. 19. The stream tube contraction, going upstream from the inlet aperture to the freestream is shown as a function of angle-of-attack for freestream Mach numbers of interest. This represents "lost" capture area with an attendant increase in inlet size required in order to maintain the mass capture at 0 -degrees angle-of-attack. For example, the inlet capture area for a flight Mach number of 1.6 at 4-degrees angle-of-attack needs to be at least $8 \%$ larger than that for a freestream, or under-wing integration.

Figure 20 shows the effect of angle-of-attack on the inlet critical-point total pressure recovery. As with the 
mass capture, the curves are well-behaved for subsonic flight conditions and begin to exhibit non-linear behavior beyond 4-5-degrees for supersonic cases. The Mach 1.8 case falls well below the others, due to the aforementioned effects of increased over-wing Mach number, and over-sped off-design operation. Again, this is a unique aspect of over-wing inlet installation and must be carefully considered for operational designs. Isolated inlet pressure recovery again closely matches that of the installed inlet, at least at the low angles-of-attack where a comparison is available.

Finally, distortion at the inlet critical point for these cases is presented in Fig. 21 and is seen to increase exponentially beyond about 4-degrees. The Mach 1.6 point at 8 -degrees angle-of-attack is off-scale at 55\%, but was presented in an AIP contour plot sequence in Fig. 12 that clearly shows an abrupt transition to poor flow quality between 6-and 8-degrees angle-of-attack. The only other remarkable feature is that isolated inlet distortion values are higher than those of the installed inlet at some conditions. Again however, the distortion parameter being used is meant only to demonstrate trends, so a conclusion regarding these differences cannot be made.

\section{Installed Inlet Performance at 0-and 4-deg AOA Over Mach Range}

Inlet performance over the range of Mach numbers tested appears in Fig. 22. The circles and squares are for angles-of-attack of 4-and 0-degrees respectively. The 4-degree case is intended to best represent performance in flight. The zero angle-of-attack curves as well as the isolated inlet points may be used as a basis for discussion of installation effects. Referring back to Fig.s 18, 20, and 21, it can be seen that values at zero angle-of-attack were interpolated or extrapolated based on the data available for all subsonic Mach numbers, and Mach 1.4. First, in Fig. 22a, the isolated inlet mass capture matches that of the installed inlet at 0-degrees angle-of-attack. The effect of over-wing installation on mass capture is evident as Mach number increases and the curve for 4-degrees angle-ofattack trends slightly lower at Mach 1.6 and 10\% lower at Mach 1.8. As stated previously, a mass flow ratio of unity would be expected at Mach 1.8 for the 0 -degree and isolated inlet cases, and possible explanations for this discrepancy were given above.

Inlet critical-point pressure recoveries over the Mach number range are shown in Fig. 22b. Two reference curves are also shown; MIL STD-E-5007D which tends to be optimistic, and normal-shock or pitot-inlet recovery. There are two features worth noting here. First is the dip in recovery at Mach 1.4 that is presumably caused by offdesign shock structure and is present in all cases, isolated and installed. The second, and more significant feature is the $6 \%$ deficit in recovery at Mach 1.8 for the installed inlet at 4-degrees angle-of-attack. This is the consequence of the over-wing installation, due to increased local Mach number downstream of the leading edge expansion. From Mach 1.2 to 1.6, pressure recovery at 4-degrees angle-of-attack ranges from 1 to $2 \%$ below that at 0 -degrees and is within a few percent of the MIL STD-E-5007D value.

Distortion over the Mach number range appears in Fig. 22c. Using the 0-degree angle-of-attack as a basis, values at 4-degrees range from $12 \%$ higher at the Mach 1.6 design point, to $28 \%$ higher at Mach 1.8. It is tempting to categorize this as another consequence of over-wing installation, and it obviously is at the present scale, but as will be discussed in a subsequent section, distortion levels are a strong function of scale, and the effect of angle-ofattack may decrease as Reynolds number increases.

\section{E. Mach 0.25 Cases}

A limited number of runs were made at Mach 0.25. For these cases the MFP was un-choked and as stated earlier, mass flow rate information was compromised by differences in pressure ratio measurements between the calibration and test. The installed inlet was run at 0 -and 10 -degrees angle-of-attack at zero yaw. The isolated inlet was run at -2,3, and 8-degrees yaw at 0 -degrees angle-of-attack. In these runs, the mass flow rate was limited by the available pressure ratio, and for a range of plug positions beginning at full-open, did not vary. As the plug was drawn closed, mass flow was reduced in each case to at least $20 \%$ of the maximum value reported by the flow plug calibration. AIP rake data revealed no flow separation or other anomalies at the angle-of-attack and yaw extremes.

\section{Analysis of the Effect of Scale on Inlet Operation}


Given the low Reynolds number of the present experiment relative to flight, it was of interest to examine the effect of Reynolds number on inlet performance. The isolated inlet configuration with no bleed was analyzed at three different scales: the test scale (1/43), a "reference scale" (1/3), and full scale, all at the Mach 1.56 freestream condition. Corresponding Reynolds numbers based on the AIP diameter were approximately $0.6,8$, and 22 million respectively. The Reynolds numbers are not exactly proportional to scale, as the $1 / 3$ and full-scale cases were run at slightly different flight conditions, and $8 \times 6$ conditions were used for the $1 / 43$-scale case. A detached eddy simulation (DES) was performed at all three scales using the Wind-US V2.0 Reynolds-Averaged Navier-Stokes code (Ref. 5). The isolated inlet geometry was simulated to the AIP station, downstream of which a short cylindrical section and converging-diverging nozzle were added in order to back-pressure the solutions. The grid used, consisting of approximately 33 million grid points in 151 blocks is shown in Fig. 23. Note the two-degree toe-out inherent in the inlet geometry. This was compensated for by applying a two-degree angle to the inflow, thereby matching the experimental data which was taken at a two-degree yaw angle. The DES calculations were done over a range of back-pressures in an effort to obtain critical-point solutions for each scale. The resolution in back-pressure was not as fine as in the experiment, but solutions near the critical point were obtained for each scale. Mach number and total pressure contours presented were generated using instantaneous values from the time-varying DES solutions.

Figure 24 presents critical-point Mach number contours on the centerline plane and total pressure recovery contours at the AIP for the three different scales. Figure 24a includes the corresponding experimental total pressure recovery contours at the AIP, where good agreement in the average total pressure recovery as well as qualitatively in the flow deficit region is seen, lending some measure of validation to the DES calculations. In Fig.s $24 \mathrm{~b}$ and 24c, the lowenergy flow at 180-degrees, apparent at the test-scale, is almost completely eliminated at the larger scales, and there is little difference in the $1 / 3$-scale and full-scale results, both exhibiting a significant increase in pressure recovery over the 1/43-scale result. These results are consistent with the conclusions of Norby ${ }^{6}$ wherein adverse effects on inlet performance were seen for Reynold's numbers less than 1 million. The present results also indicate that boundary-layer bleed, used in the experiment to control the low-energy region at 180-degrees, may not be needed at larger scale.

\section{Summary and Conclusions}

Diffuser bleed was effective at mitigating diffuser boundary-layer separation. At the nominal design conditions of Mach 1.6 and 4-degrees angle-of-attack, a mere one-percent diffuser bleed improved recovery by approximately $4 \%$ and reduced distortion by at least $30 \%$ for both the installed and isolated configurations.

Sensitivity of inlet performance to yaw angle increased with both flight Mach number and angle-of-attack. At Mach 1.6, operational yaw angle limits based on abrupt increases in distortion, and reductions in recovery were evident, and the operational range narrowed as angle-of-attack increased. At the design angle-of-attack of 4-degrees, this range was +/-4-degrees and performance was relatively insensitive to yaw angle in this range, however the best performance was obtained at low positive yaw angles.

Performance at flight Mach numbers from 1.2 to 1.6 is relatively insensitive to angle-of-attack for anglesof-attack of 4 or less. At Mach 1.8, mass flow ratio and recovery decrease immediately as angle-of-attack increases from 0 , indicative of the effect of wing leading edge expansion on the local inlet Mach number. For a given engine airflow requirement, inlet size must be increased to accommodate the stream tube expansion at the wing leading edge. At the design condition of Mach 1.6 and 4-degrees angle-of-attack, the inlet capture area required would be at least $8 \%$ larger than that of an isolated, or under-slung configuration.

Over-wing installation effects were evident over the range of supersonic flight Mach numbers tested, based on comparisons between 4-degree angle-of-attack cases and installed and isolated cases at 0 -degrees. The penalty for over-wing installation was nominally a $2 \%$ reduction in pressure recovery up to the design Mach number of 1.6, increasing to approximately $6 \%$ at Mach 1.8 . Inlet critical mass flow ratio was also affected by over-wing 
installation, trending slightly lower at Mach 1.6, and 10\% lower at Mach 1.8. The increased deficits in mass flow ratio and recovery at Mach 1.8 are attributed to over-wing stream expansion at angle-of-attack.

CFD results indicate a significant benefit of scale to improving inlet performance and flow quality. At full scale, inlet boundary layer bleed may not be required.

Over-wing inlet installation is a viable means to mitigate the contribution of propulsion system integration to sonic boom. Angle-of-attack and yaw limits must be carefully explored however, along with the system implications of increased inlet size and reduced pressure recovery due the wing leading edge expansion.

\section{References}

1. Magee, T.E., Fink, L.E., Fugal, S.R., Adamson, E.E., and Shaw, S.G.: Boeing N+2 Supersonic Experimental Validation Phase II Program. 32nd AIAA Applied Aerodynamics Conference, 16-20 June 2014, Atlanta, GA, AIAA 2014-2137.

2. Slater, J.W.: Improvements in Modeling $90^{\circ}$ Bleed Holes for Supersonic Inlets. NASA TM-2009-215597, June, 2009.

3. Soeder, R.H.: NASA Lewis 8- by 6-Foot Supersonic Wind Tunnel User Manual. NASA TM-105771, February, 1993

4. Arrington, E.A.: Calibration of the NASA Glenn 8- by 6-Foot Supersonic Wind Tunnel (1996 and 1997 Tests). NASA/CR—2012-217270, January, 2012.

5. Towne, C.E. “Wind-Us User's Guide, Version 2.0," NASA TM-2009-215804, 2009.

6. Norby, W.P.: Small Scale Inlet Testing for Low Cost Screening Applications, AIAA 90-1926, 1990.

Table 1. Freestream conditions in the 8-by 6-Foot Supersonic Wind Tunnel.

\begin{tabular}{|c|c|c|c|c|c|}
\hline $\begin{array}{c}\text { Nominal } \\
\text { Mach } \\
\text { Number, } \\
M_{0}\end{array}$ & $\begin{array}{c}\text { Test Section } \\
\text { Mach } \\
\text { Number, } \\
M_{\text {Ts }}\end{array}$ & $\begin{array}{c}\text { Dynamic } \\
\text { Pressure, } \\
Q_{0}(\mathrm{psfa})\end{array}$ & $\begin{array}{c}\text { Total } \\
\text { Pressure, } \\
P_{\text {TO }} \text { (psia) }\end{array}$ & $\begin{array}{c}\text { Total } \\
\text { Temperature, } \\
T_{\text {To }}(\text { deg } \mathrm{R})\end{array}$ & $\begin{array}{c}\text { Unit } \\
\text { Reynold's } \\
\text { Number, } \\
R e\left(10^{-6} / \mathrm{ft}\right)\end{array}$ \\
\hline 0.8 & 0.801 & 724 & 17.09 & 592 & 4.29 \\
\hline 0.9 & 0.894 & 811 & 16.92 & 593 & 4.41 \\
\hline 0.95 & 0.946 & 855 & 16.86 & 594 & 4.48 \\
\hline 1.2 & 1.188 & 1027 & 17.23 & 601 & 4.74 \\
\hline 1.4 & 1.355 & 1132 & 18.28 & 610 & 4.88 \\
\hline 1.6 & 1.559 & 1246 & 20.35 & 625 & 5.01 \\
\hline 1.8 & 1.782 & 1313 & 22.93 & 645 & 5.10 \\
\hline
\end{tabular}

Table 2. Sting deflections and model angle-of-attack.

\begin{tabular}{|c|c|c|}
\hline $\begin{array}{c}\text { Nominal } \\
\text { Angle-of- } \\
\text { Attack, } \\
\alpha \text { (deg) }\end{array}$ & $\begin{array}{c}\text { Sting } \\
\text { Deflection, } \\
\Delta \alpha \text { (deg) }\end{array}$ & $\begin{array}{c}\text { Corrected } \\
\text { Model Angle- } \\
\text { of-Attack, } \\
\alpha^{\prime} \text { (deg) }\end{array}$ \\
\hline-2 & -0.46 & -2.46 \\
\hline 0 & -0.15 & -0.15 \\
\hline 2 & 0.15 & 2.15 \\
\hline 4 & 0.46 & 4.46 \\
\hline 6 & 0.76 & 6.76 \\
\hline 8 & 1.07 & 9.07 \\
\hline
\end{tabular}


Table 3. Test matrix for installed inlet with diffuser bleed. " $\mathrm{S}$ " denotes both installed and isolated inlet.
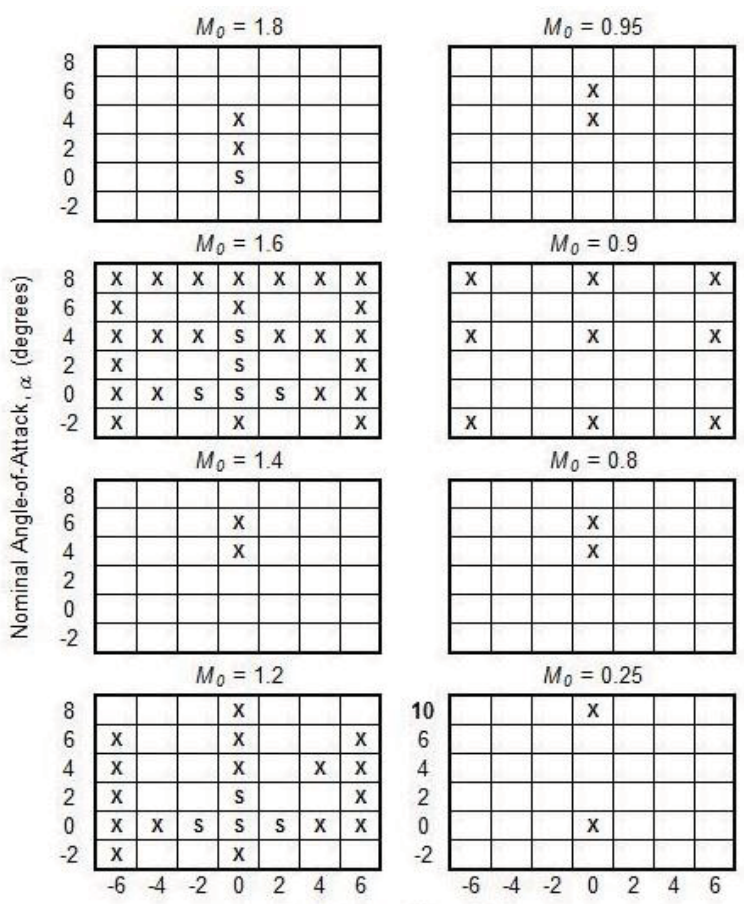

Yaw Angle, $\beta$ (degrees) 


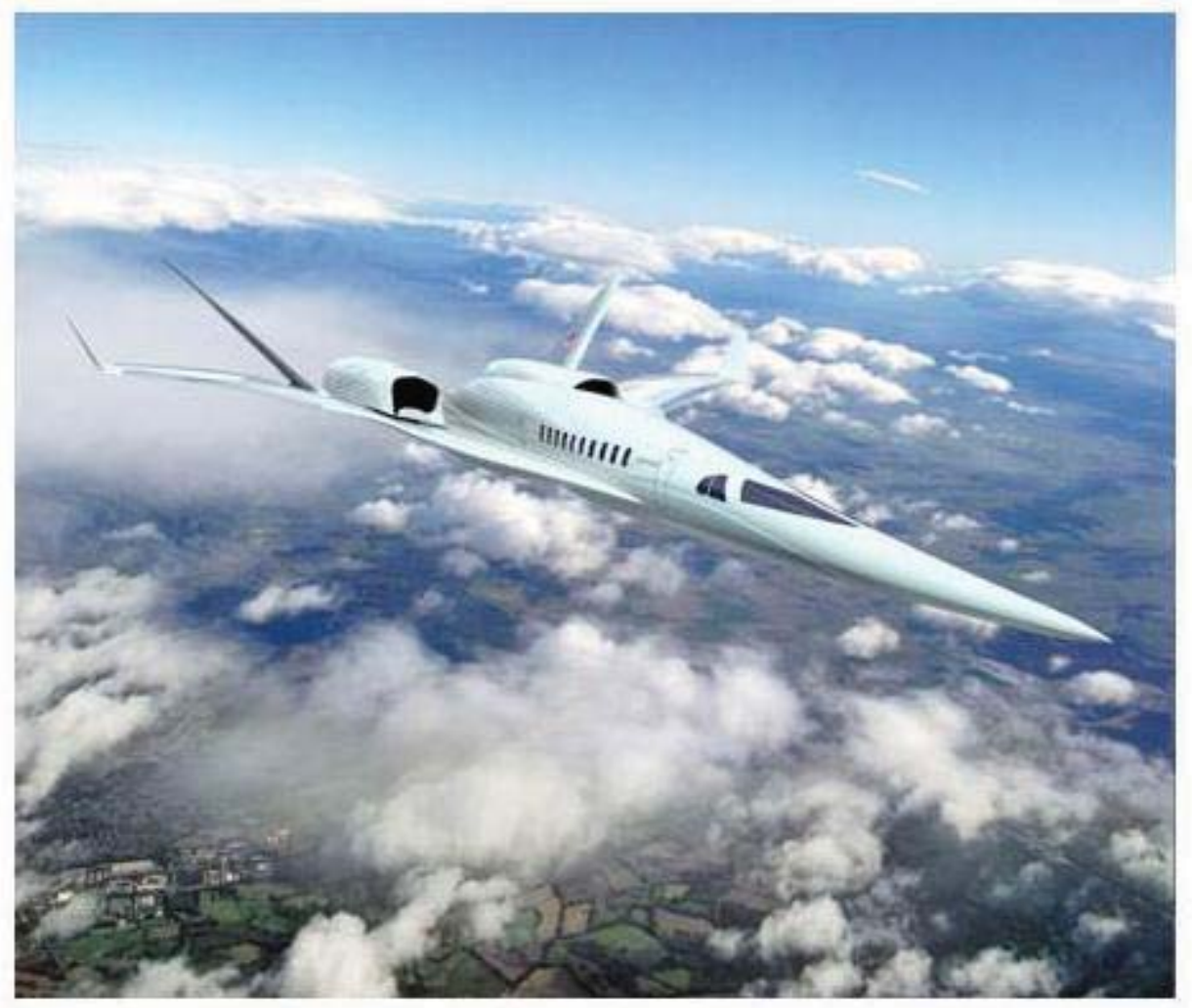

Figure 1. Boeing QEVC concept with over-wing inlet installation.
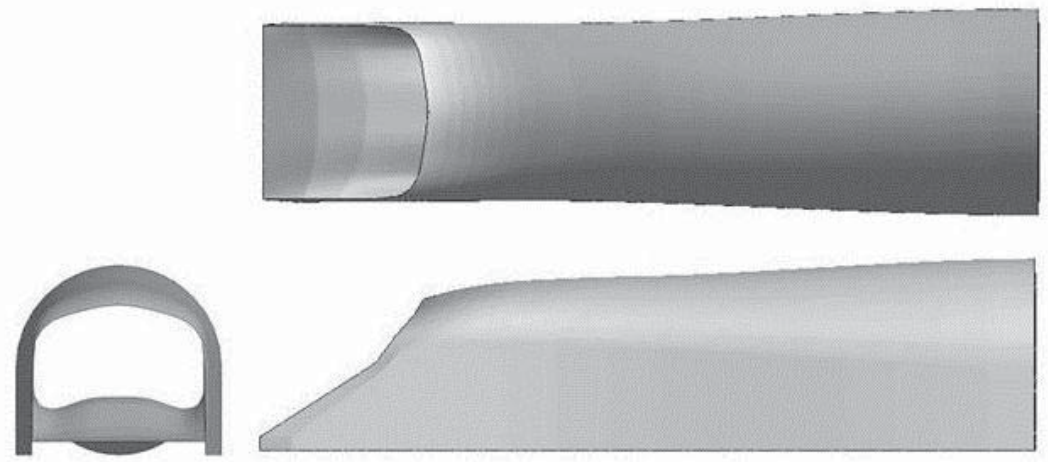

Figure 2. Boeing Elliptical Cowl Ramp Inlet (ECRI) design. 


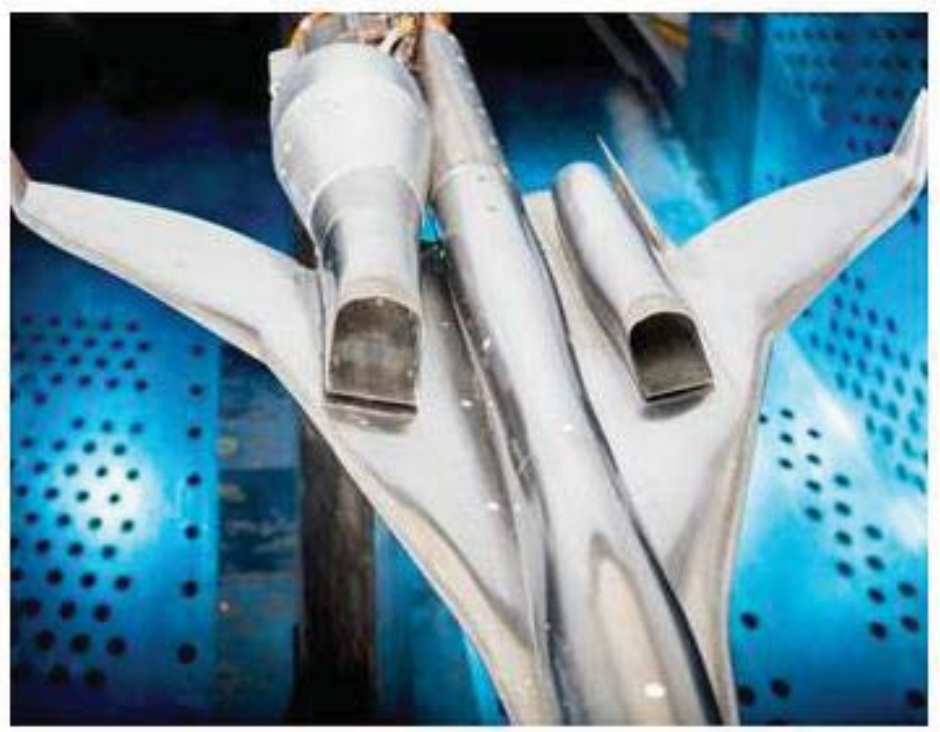

Figure 3. QEVC model installed in the 8x6 SWT with inlet model on starboard side.

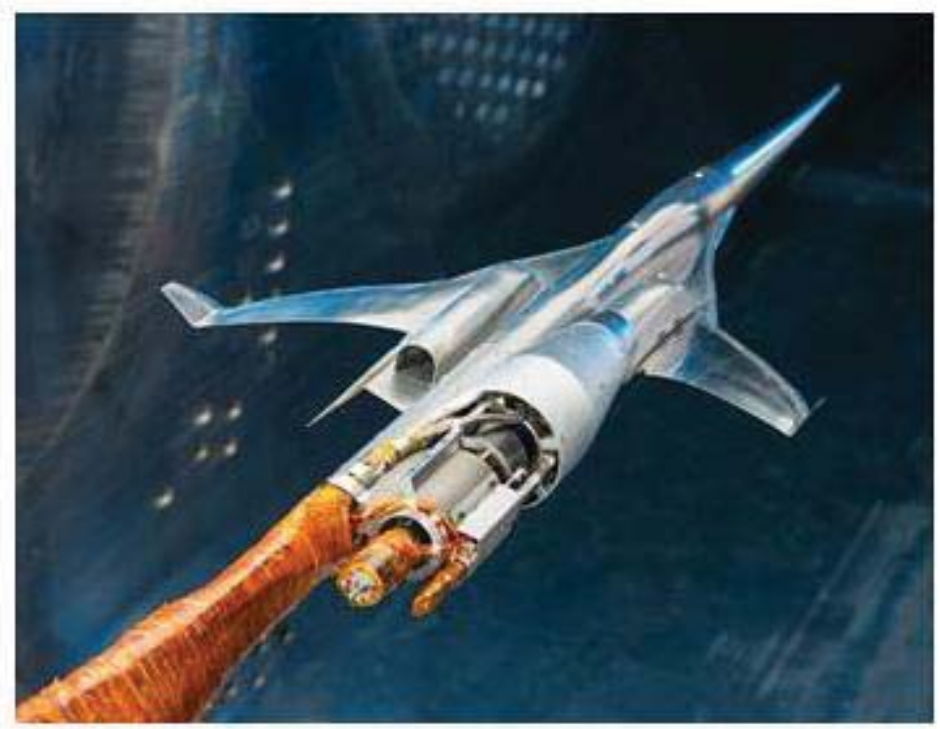

Figure 4. QEVC model installed in the 8x6 SWT showing mass flow plug assembly. 


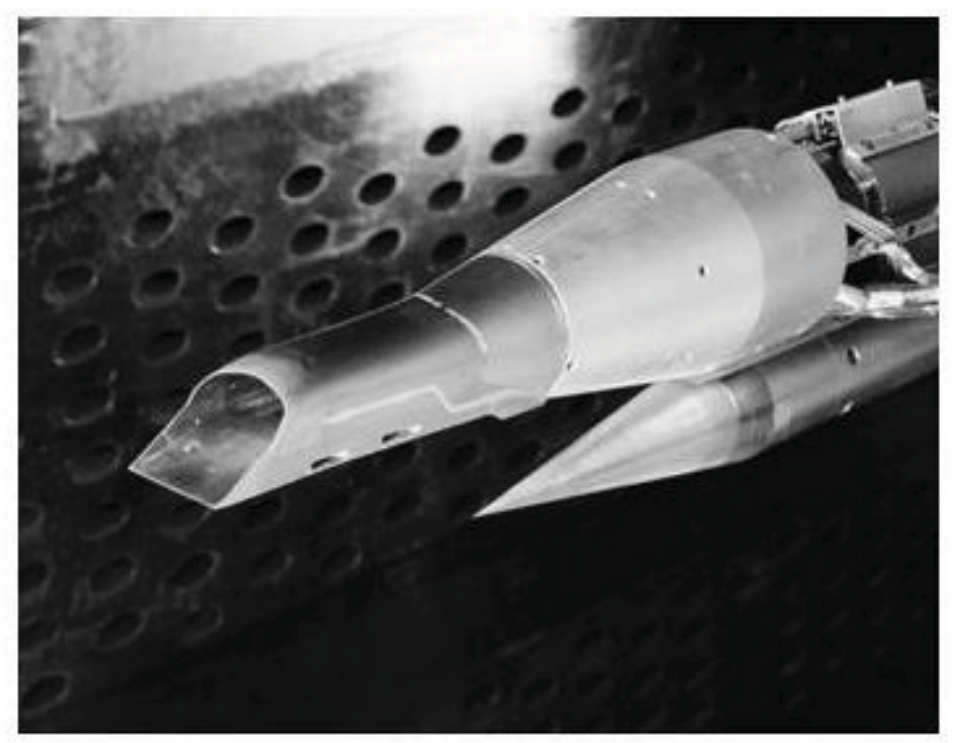

Figure 5. QEVC isolated inlet configuration installed in the 8x6 SWT.

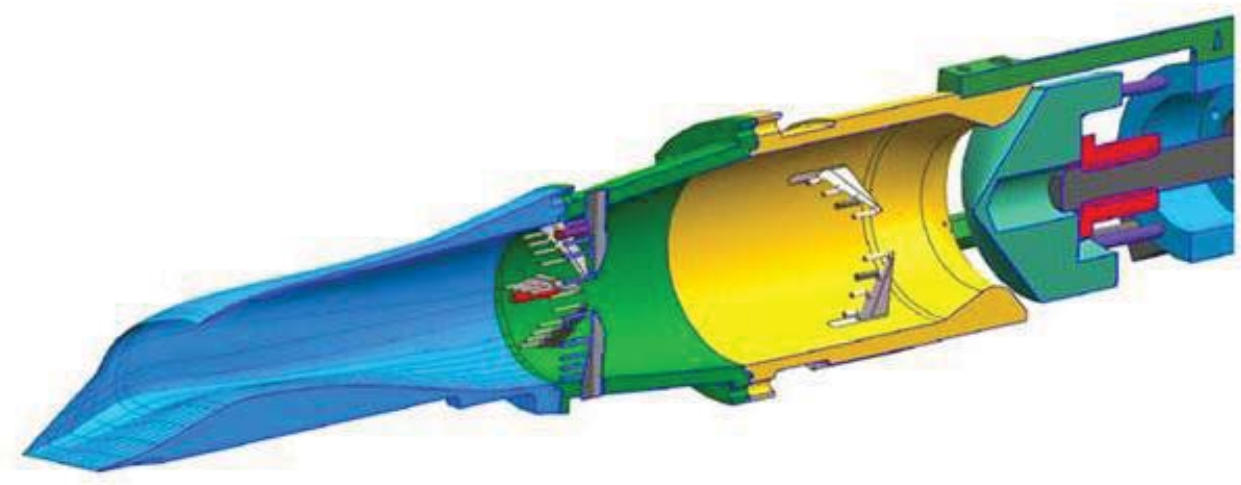

Figure 6. Cut-away view of the QEVC inlet and mass flow plug assembly. 

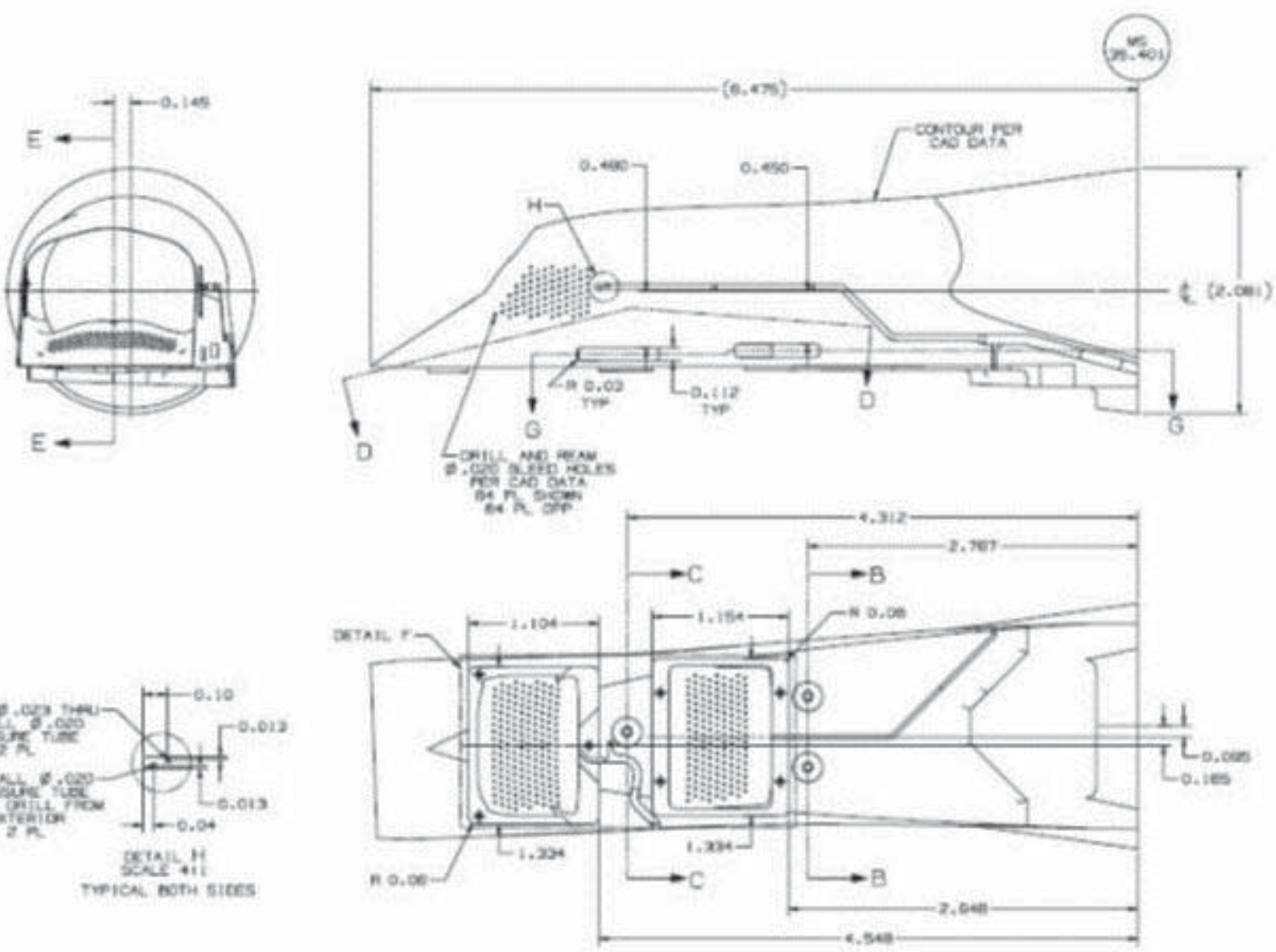

Figure 7. Porous-bleed regions on the ramp and sidewalls. 


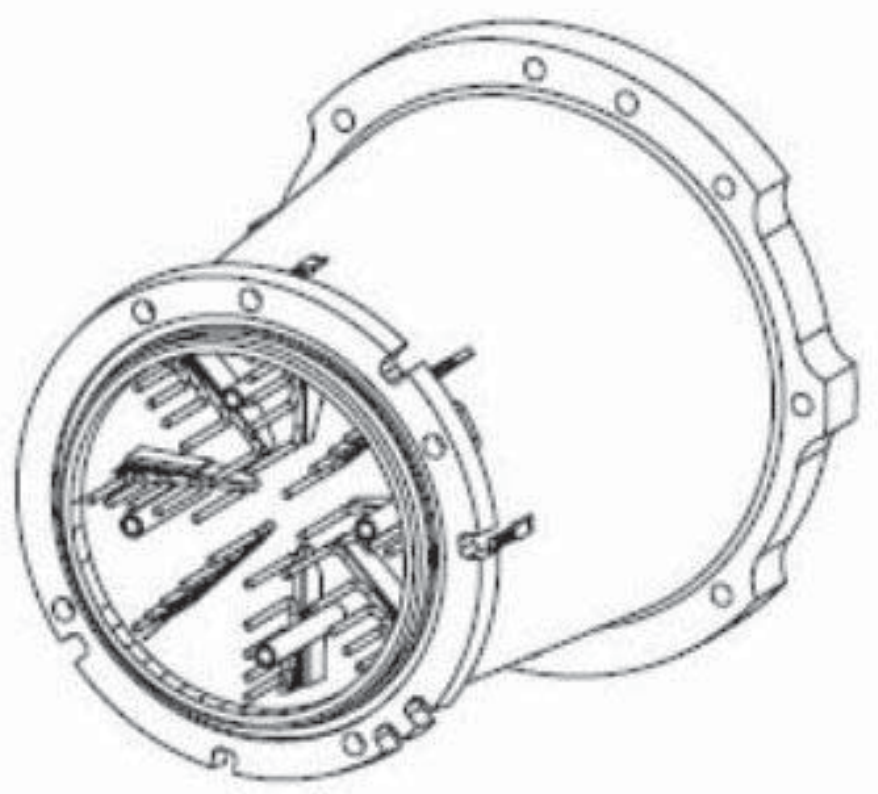

Figure 8. Adapter section and AIP rakes.

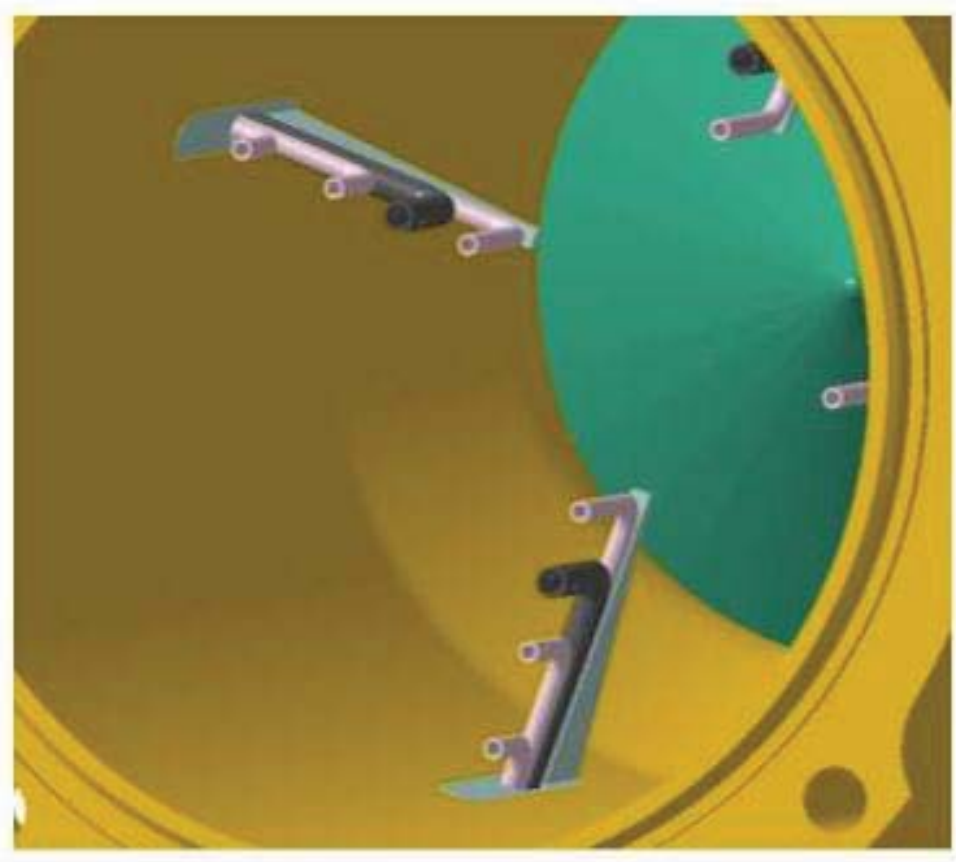

Figure 9. MFP rakes. 


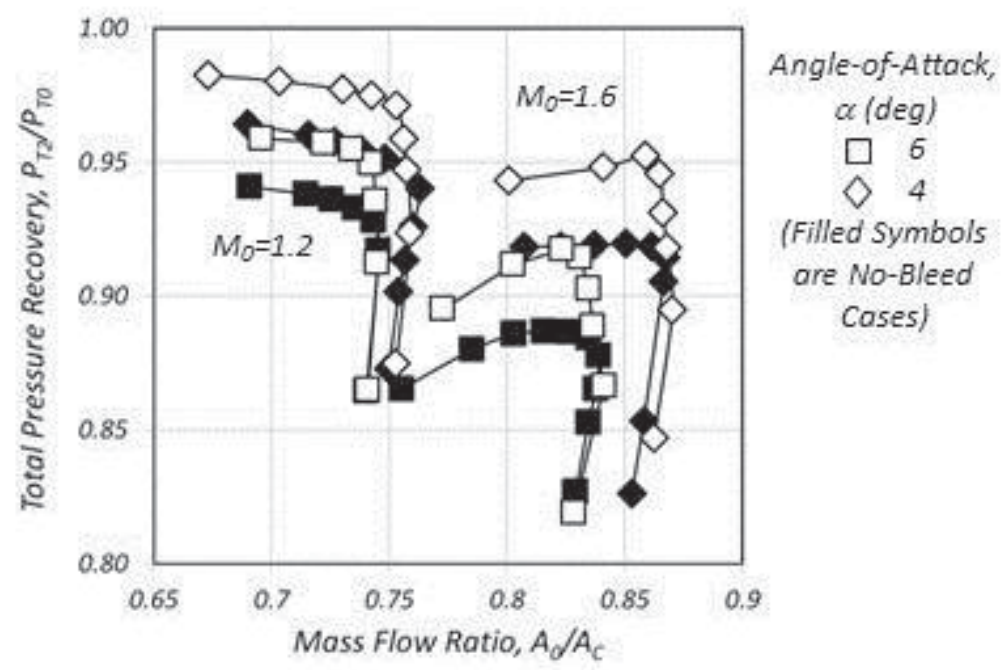

Figure 10. Installed inlet airflow characteristics at zero yaw angle showing the effect of diffuser bleed.

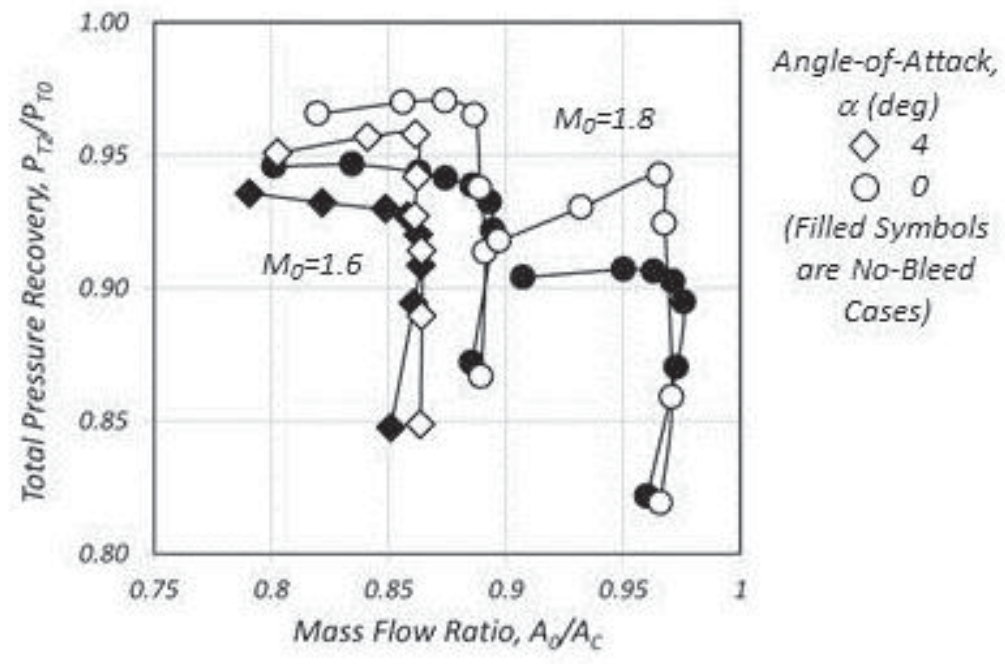

Figure 11. Isolated inlet airflow characteristics at zero yaw angle showing the effect of diffuser bleed. 


$$
\alpha=8
$$
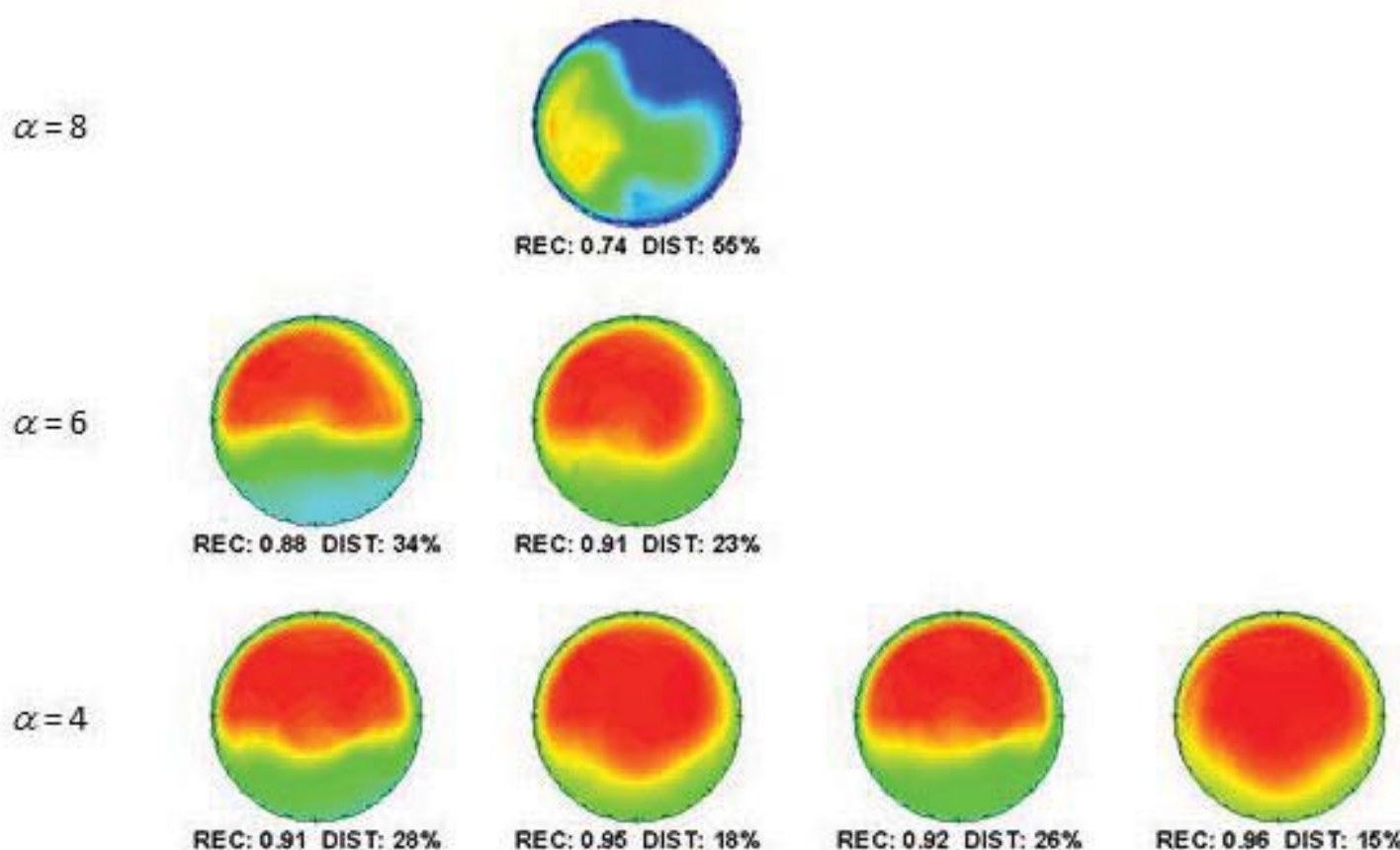

REC: 0.98 DIST: $18 \%$

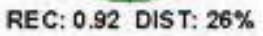

REC: 0.96 DIST: $15 \%$

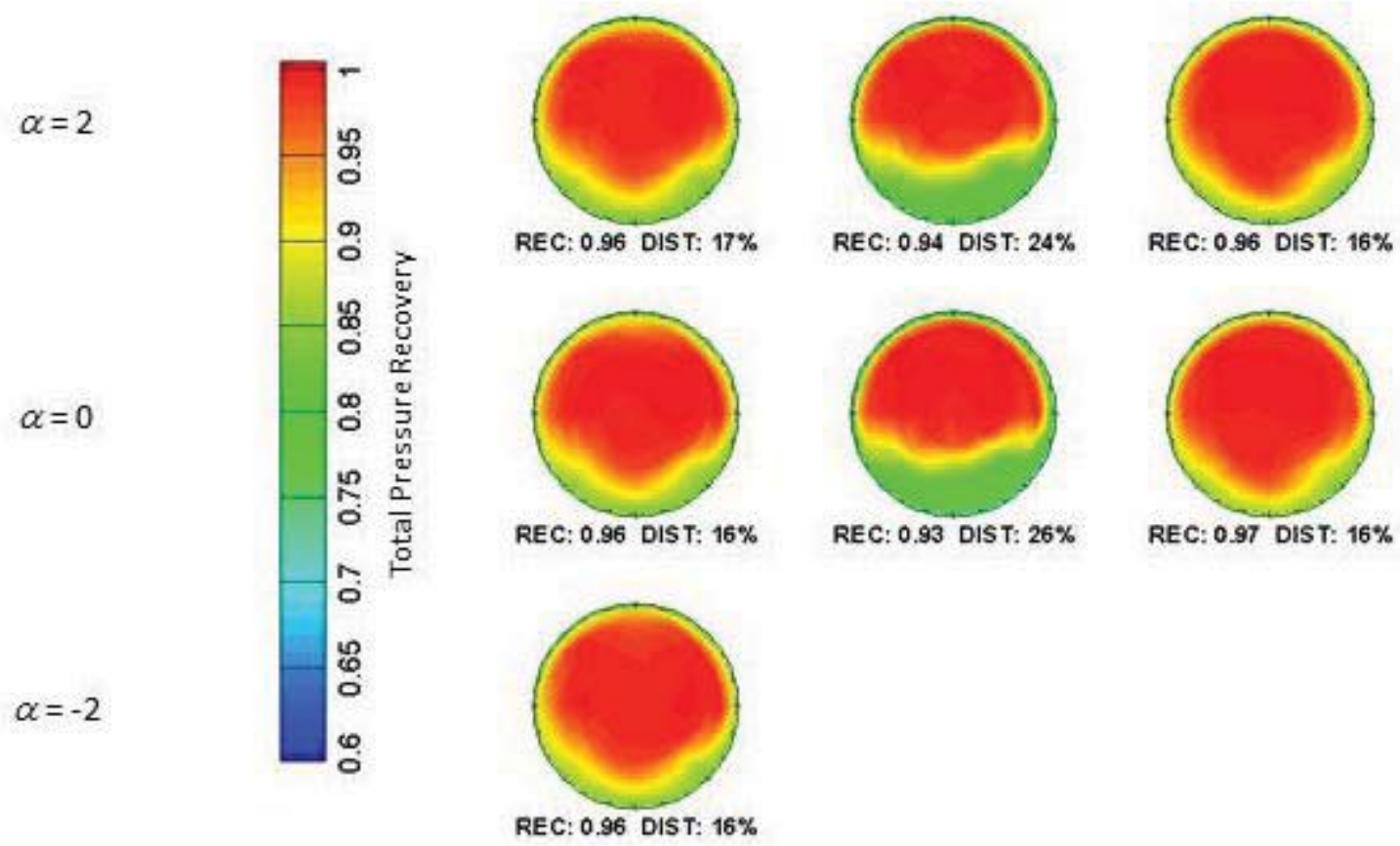

No Bleed

$\sim 1 \%$ Bleed

No Bleed

$\sim 1 \%$ Bleed Installed Isolated

Figure 12. Total pressure recovery contours at the inlet critical point, Mach 1.6, zero yaw angle, looking upstream. 


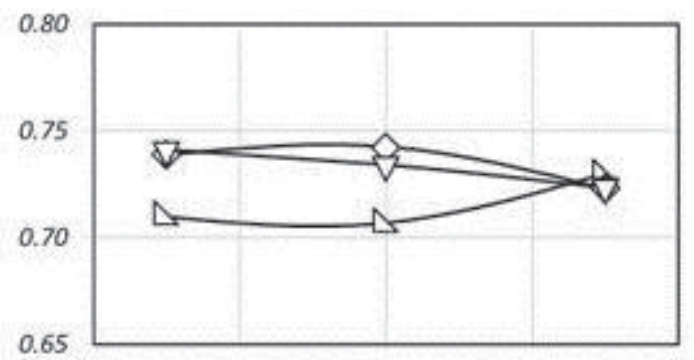

c) $\mathrm{M}_{0}=.9$

Angle-of-Attack,

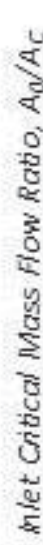

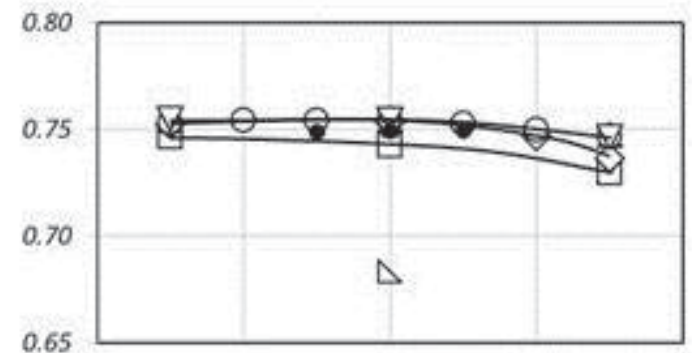

$\alpha$ (deg)

$\triangle 8$

ㅁ. 6

$\diamond 4$

$\triangle 2$

O 0

$\begin{array}{lll}\nabla & -2\end{array}$

(Filled Symbols

b) $M_{0}=1.2$

are Isolated inlet)

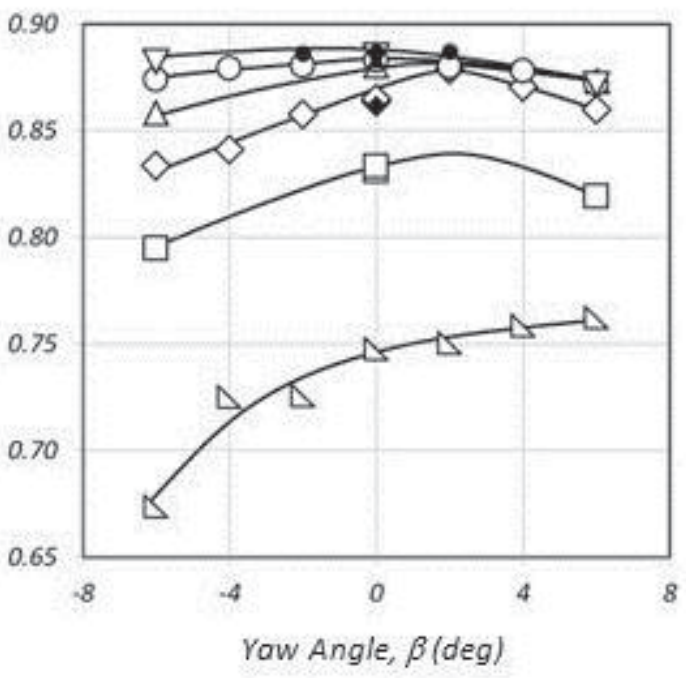

a) $M_{0}=1.6$

Figure 13. Effect of yaw angle on inlet critical-point mass flow ratio. 


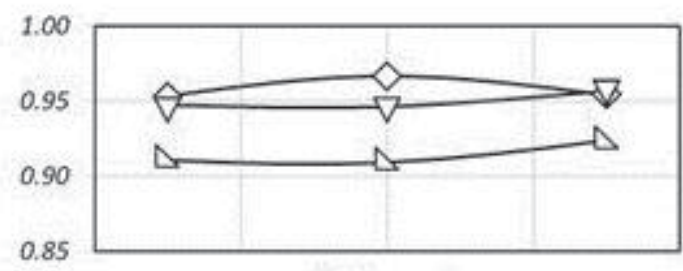

c) $\mathrm{M}_{0}=.9$

Angle-of-Attack, $\alpha$ (deg)



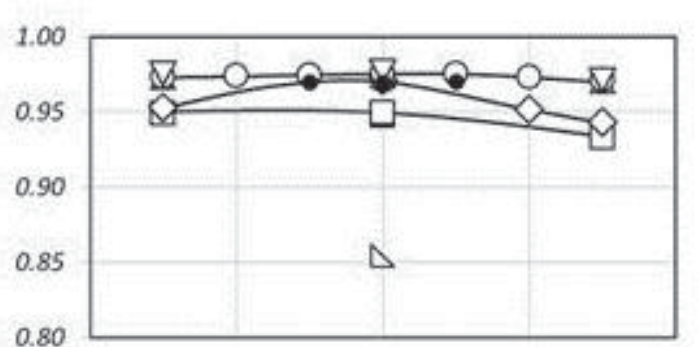

$\triangle 8$

ㅁ 6

○ 4

$\triangle 2$

00

$\nabla \quad-2$

(Filled Symbols

are Isolated

b) $M_{0}=1.2$ inlet)

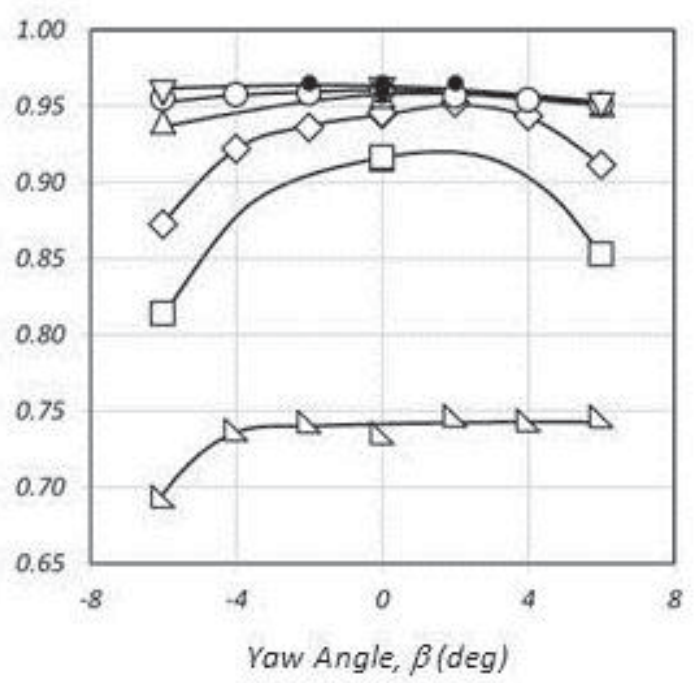

a) $\mathrm{M}_{0}=1.6$

Figure 14. Effect of yaw angle on inlet critical-point total pressure recovery. 

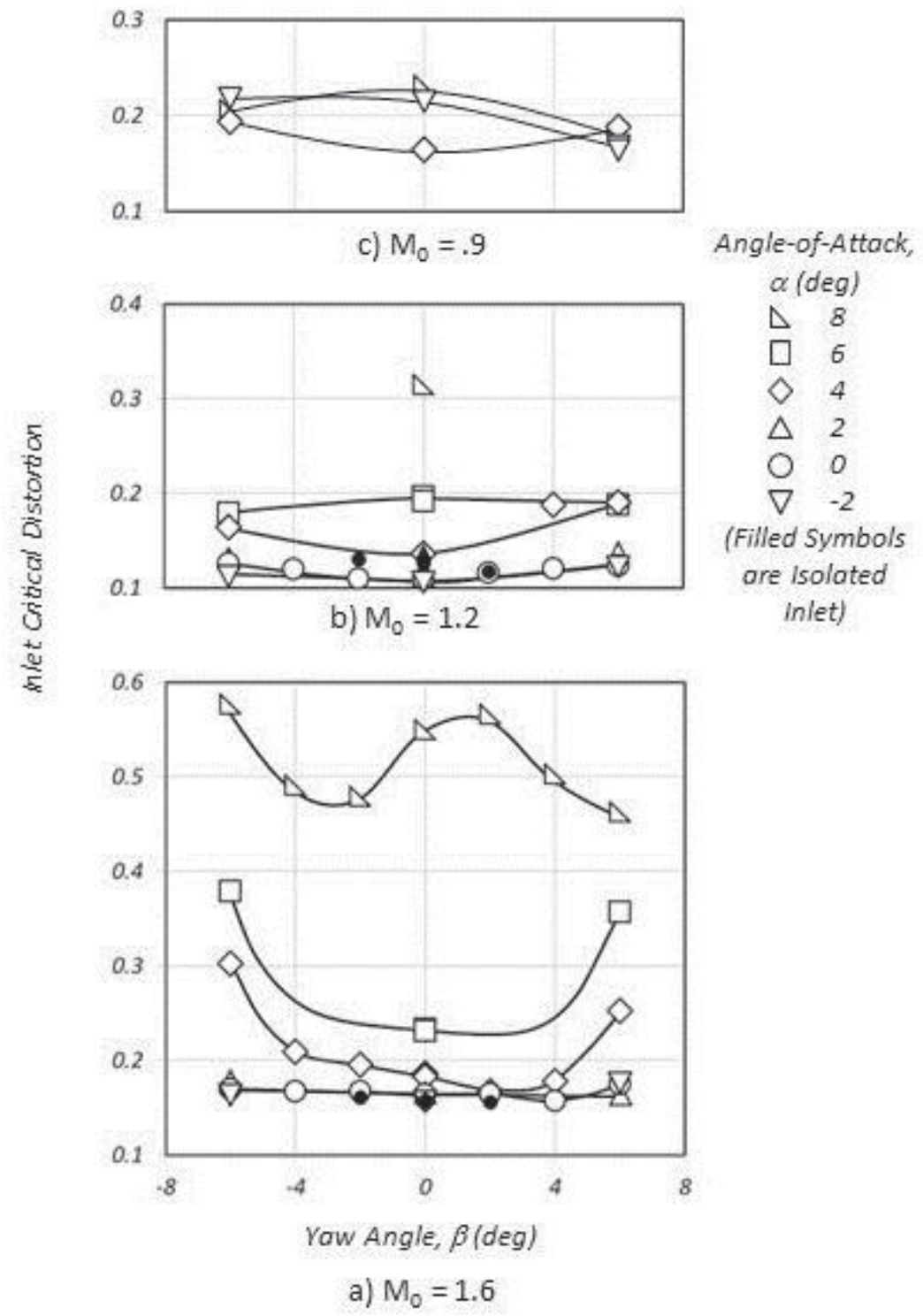

Figure 15. Effect of yaw angle on inlet critical-point distortion. 

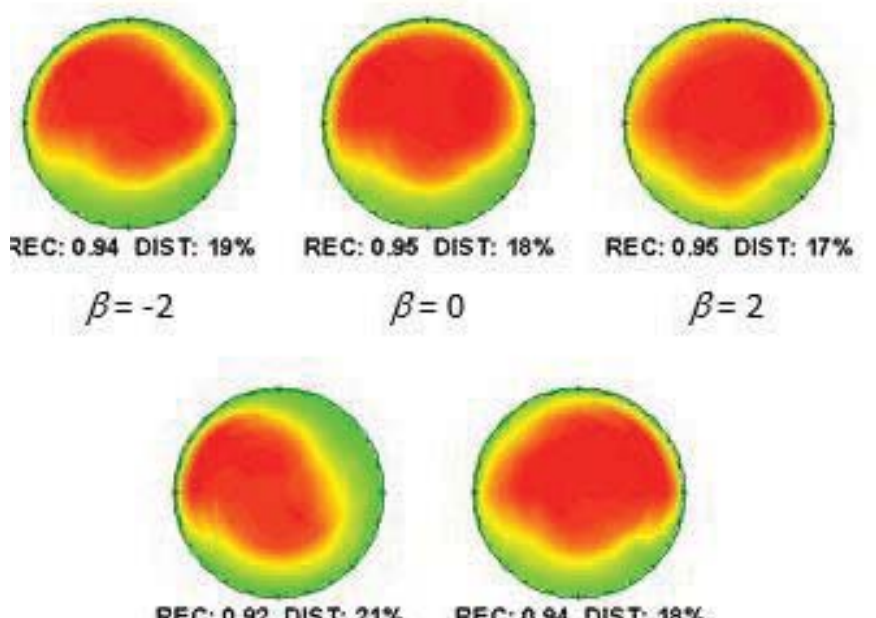

$\beta=-4$

$$
\beta=4
$$
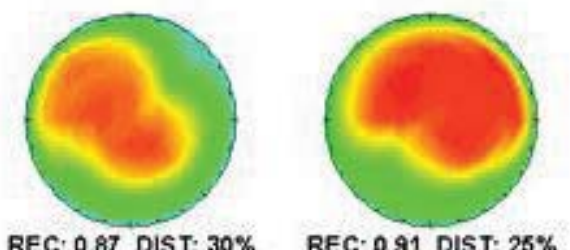

$\beta=-6$

$$
\beta=6
$$

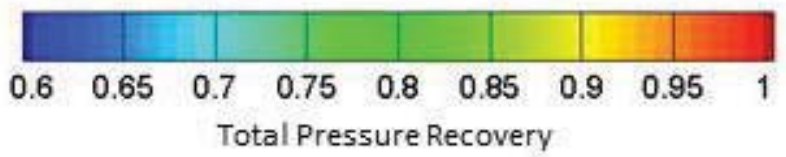

Figure 16. Total pressure recovery contours at the inlet critical point, installed inlet, $\sim 1 \%$ bleed, Mach 1.6, 4degrees angle-of-attack, looking upstream. 

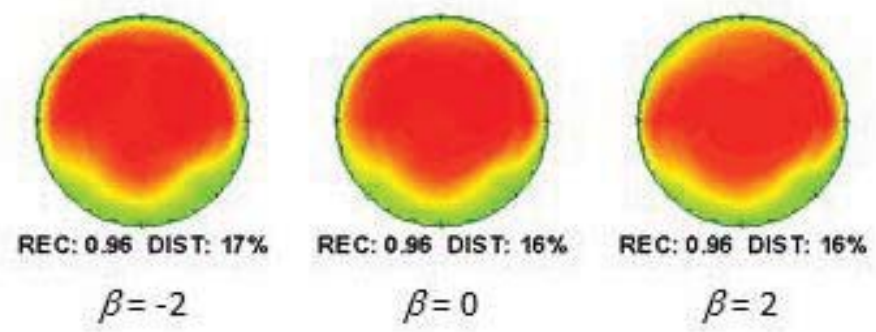

$$
\beta=-2
$$$$
\beta=0
$$$$
\beta=2
$$

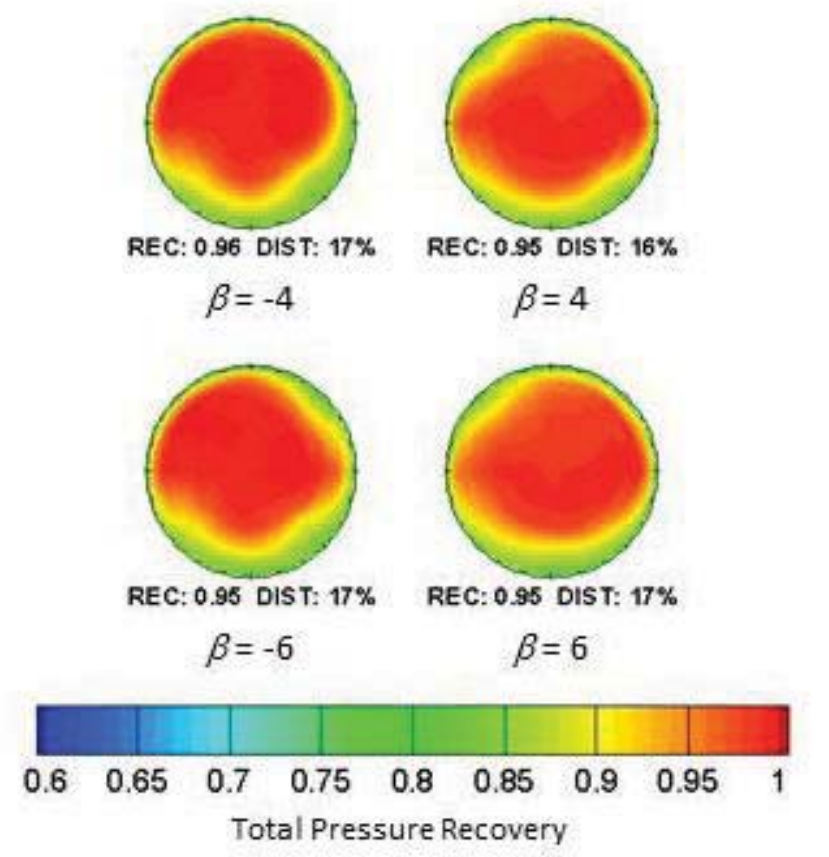

Figure 17. Total pressure recovery contours at the inlet critical point, installed inlet, $\sim 1 \%$ bleed, Mach 1.6, 0degrees angle-of-attack, looking upstream. 


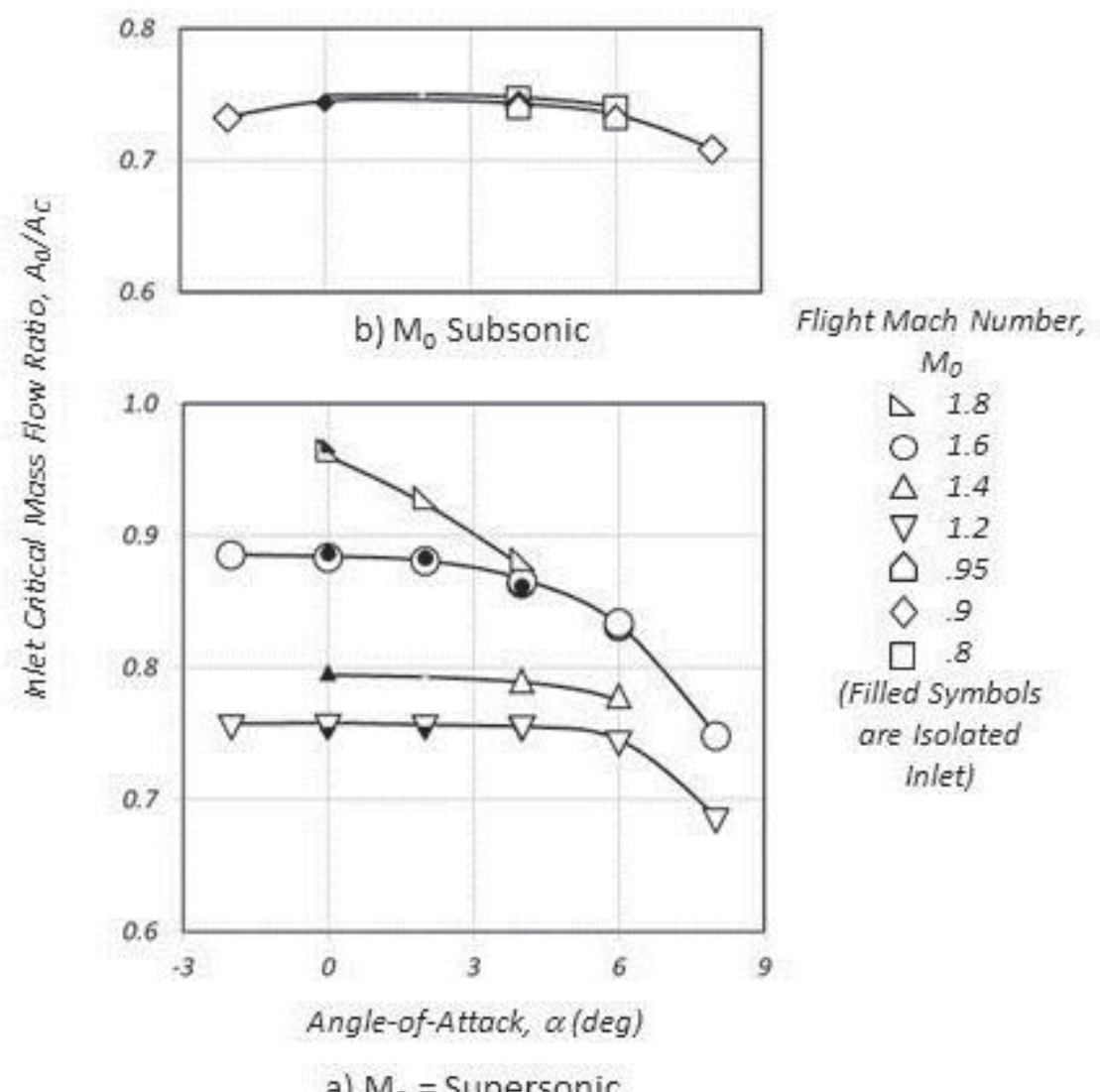

a) $M_{0}=$ Supersonic

Figure 18. Effect of angle-of-attack at zero yaw on inlet critical-point mass flow ratio.

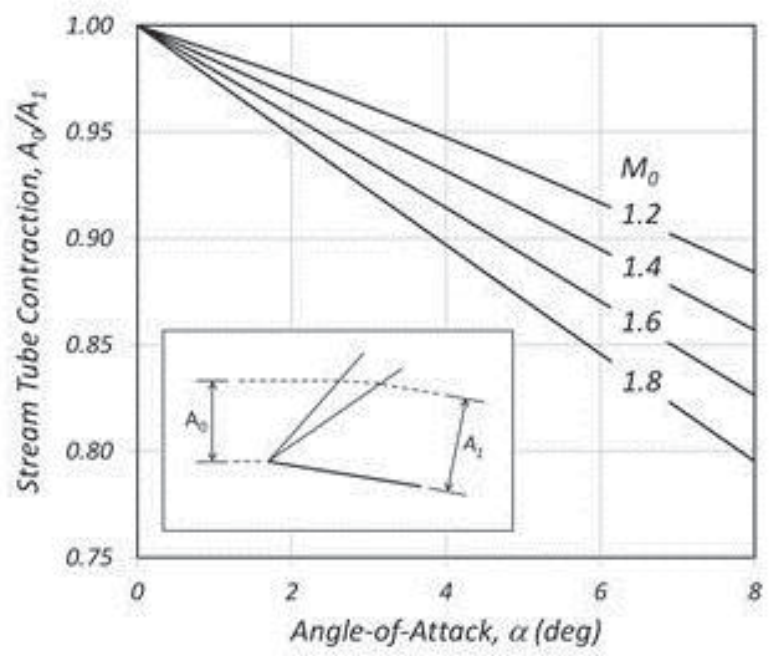

Figure 19. Effect of angle-of-attack on stream tube cross-section. 


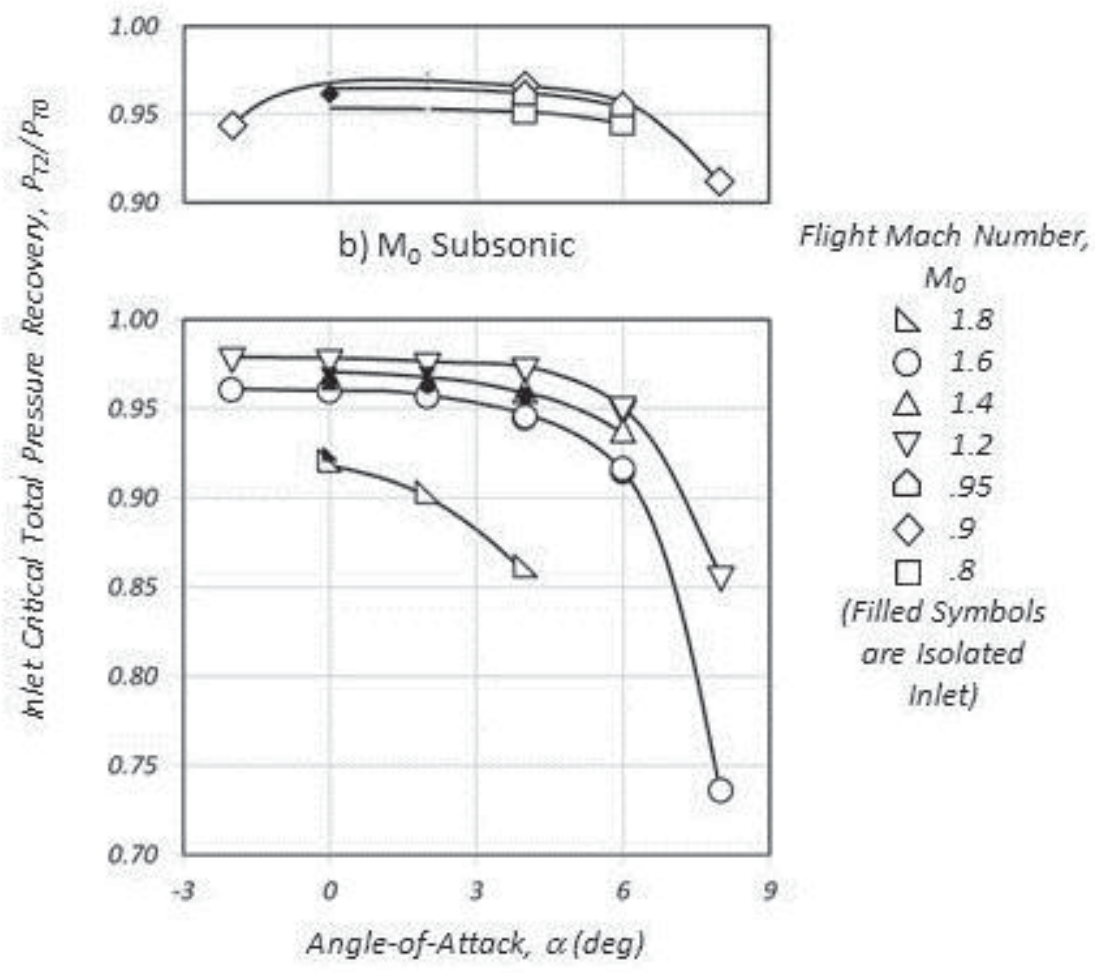

a) $\mathrm{M}_{0}=$ Supersonic

Figure 20. Effect of angle-of-attack at zero yaw on inlet critical-point total pressure recovery. 

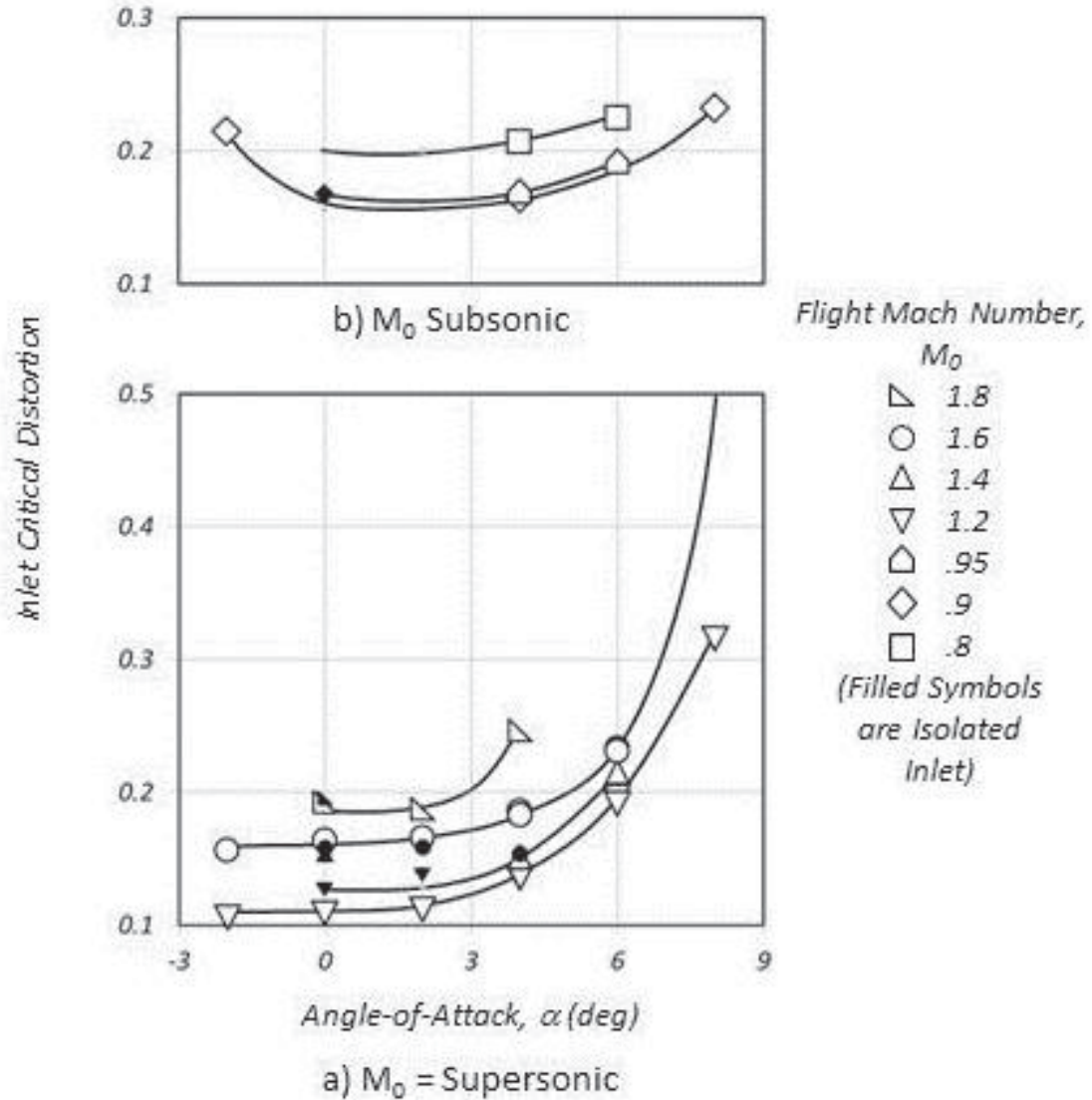

Figure 21. Effect of angle-of-attack at zero yaw on inlet critical-point distortion. 


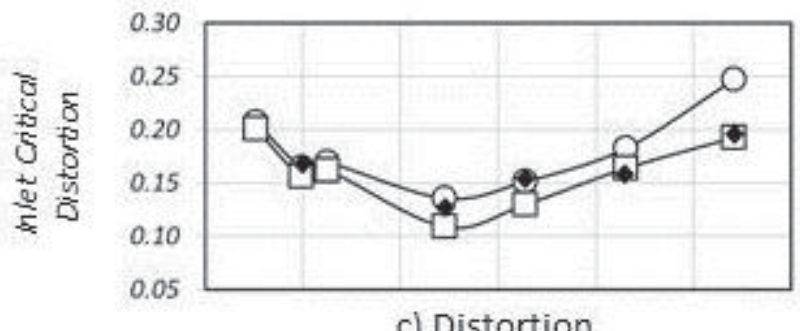

o $\alpha=4$-deg, $\beta=0-\operatorname{deg}$ (installed)

$\square^{\alpha=0 \text {-deg, } \beta=0 \text {-deg }}$ (instolled)

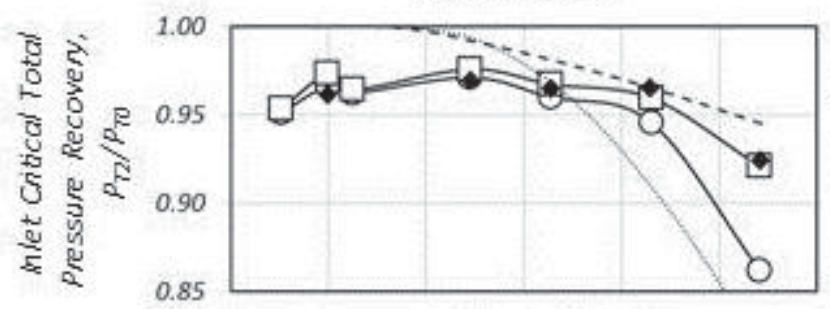

$\alpha=0$-deg, $\beta=0$-deg (isolated)

b) Recovery

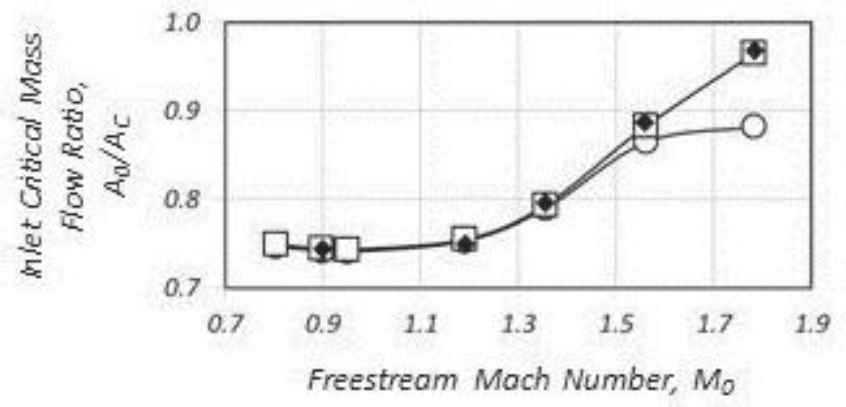

a) Mass Flow Ratio

Figure 22. Inlet performance over the Mach number range tested. 


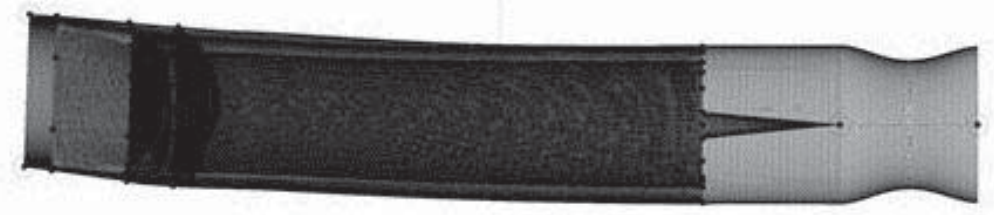

c) Top view of grid for internal flow

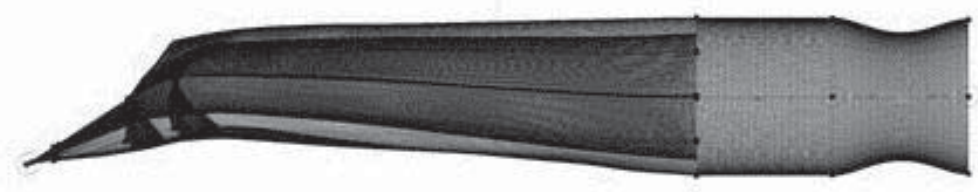

b) Side view of grid for internal flow

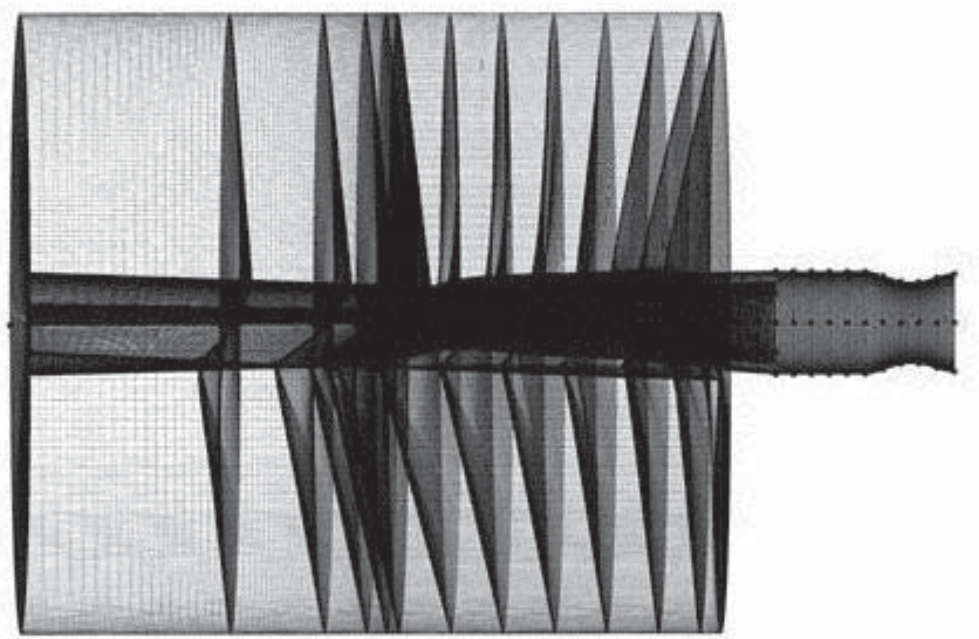

a) Complete computational grid used for the DES calculations

Figure 23. Grid used for DES calculations, 33 million grid points in 151 blocks. 


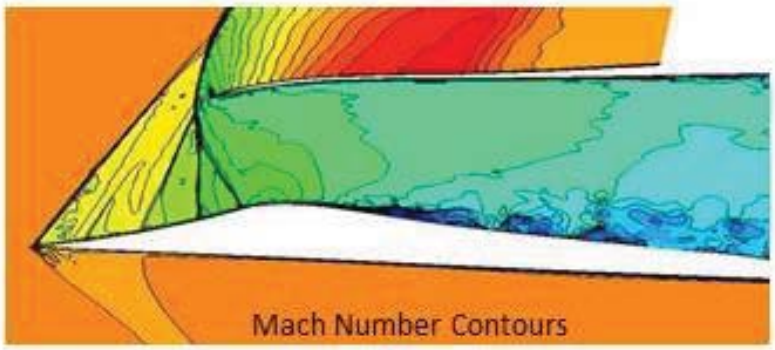

c) Full scale, $R e=22 \times 10^{6}$ based on AIP diameter
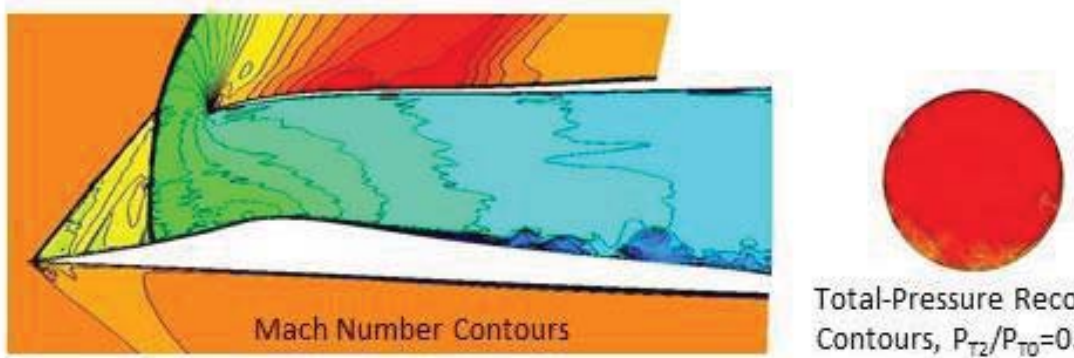

Total-Pressure Recovery Contours, $\mathrm{P}_{\mathrm{T} 2} / \mathrm{P}_{\mathrm{TO}}=0.983$

b) $1 / 3$ scale, $\operatorname{Re}=8 \times 10^{6}$ based on AIP diameter

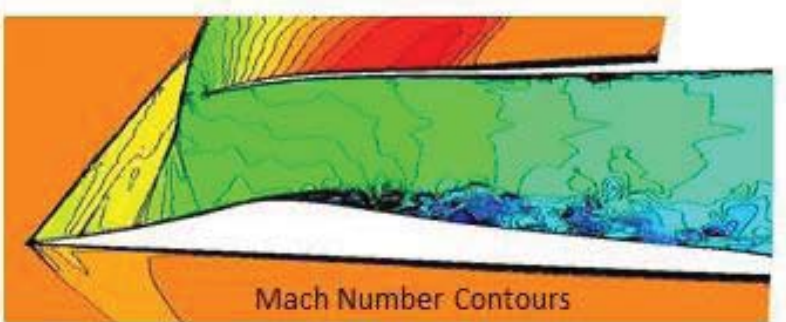

Mach Number Contours

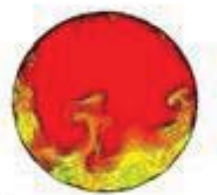

Total-Pressure Recovery Contours, $\mathrm{P}_{\mathrm{T} 2} / \mathrm{P}_{\mathrm{TO}}=0.929$

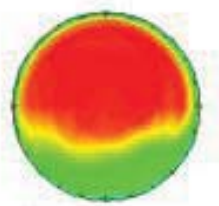

Total-Pressure Recovery Contours from Experiment, $\mathrm{P}_{\mathrm{T} 2} / \mathrm{P}_{\mathrm{TO}}=0.932$

a) $1 / 43$ scale, $R e=0.6 \times 10^{6}$ based on AIP diameter

Figure 24. DES simulations showing the effect of scale on isolated inlet flow characteristics for freestream Mach number 1.56, 0-degrees angle-of-attack, 0-degrees yaw angle, no bleed. 